\title{
La enseñanza de "Chino para Hispanohablantes" dentro del Marco Común Europeo de Referencia (MCER)
}

\author{
Consuelo MARCO MARTÍNEZ \\ Universidad Complutense de Madrid \\ cmarc@filol.ucm.es \\ Jade LEE MARCO \\ Universidad Carlos III de Madrid \\ jadeli_89@hotmail.com
}

Recibido: septiembre 2010

Aceptado: marzo 2011

\section{RESUMEN}

En este artículo nos proponemos relatar nuestra experiencia sobre cómo en la Universidad, en estrecha colaboración con la Consejería de Educación de la Comunidad de Madrid, estamos llevando a cabo la adaptación del aprendizaje, enseñanza y evaluación del "chino para hispanohablantes" al llamado Marco Común Europeo de Referencia para las Lenguas. Aunque nosotros nos centramos en los objetivos lingüísticos, intentaremos proporcionar al docente de $\mathrm{Ch} / \mathrm{LE}$ unas pinceladas teóricas y metodológicas sencillas para conseguir que sus alumnos, aparte de dominar el código lingüístico (nivel fonológico, morfosintáctico y léxicosemántico), sean también capaces de actuar de forma comunicativamente adecuada en un contexto determinado. Llevar al aula los factores socioculturales y la comunicación no verbal (paralenguaje, quinésica, proxémica y cronémica) supone trabajar con diferentes destrezas de manera integrada, las cuales facilitarán al alumno las herramientas para adquirir estrategias de análisis, comparación, contraste y reflexión acerca de realidades diversas. Esta toma de conciencia evitará caer en tópicos y prejuicios y desarrollará actitudes positivas de cara al pluralismo cultural y lingüístico de la sociedad internacional.

Palabras clave: chino, español, competencia lingüística, competencia comunicativa, competencia intercultural, objetivos lingüísticos, Marco Común Europeo, sociedad internacional.

\section{L'enseignement du "Chinois pour des hispanophones" dans le Cadre Européen Commun de Référence (CECR)}

\section{RÉSUMÉ}

Dans cet article nous nous proposons de rapporter notre expérience comment à 1'Université, dans une étroite collaboration avec la Conciergerie de 1'Education de la Communauté de Madrid, nous sommes en train d'accomplir l'adaptation de l'apprentissage, l'enseignement et l'évaluation du "chinois pour hispanophones" au Cadre Européen Commun de Référence pour les Langues. Bien que nous mous centrons dans les objectifs linguistiques, nous essaierons de fournir au professeur de $\mathrm{CH} / \mathrm{LE}$ quelques données théoriques et 
méthodologiques simples pour obtenir que ses élèves, en plus de maîtriser le code linguistique (niveau phonologique, morphosyntaxique et lexique-sémantique) soient également capables d'agir de manière communicative adéquate dans un contexte déterminé. Apporter à ce cours les facteurs sociaux-culturels et la communication non verbale (paralangage, kinésique, proxémique et chronémique) suppose de travailler avec de différentes habiletés de manière intégrée, ce qui armera l'élève à acquérir des stratégies d'analyse, de comparaison, de contraste et de réflexion sur des réalités diverses. Cette prise de conscience évitera de tomber dans des clichés et des préjugés et développera des attitudes positives face au pluralisme culturel et linguistique de la société internationale.

Mots-clés : chinois, espagnol, compétence linguistique, compétence communicative, compétence interculturelle, objectifs linguistiques, Cadre Commun Européen, société internationale.

\title{
The teaching of "Chinese for Spanish Speakers" in the Common European Framework of Reference for Languages (CEFR)
}

\begin{abstract}
The aim of this article is to give information of our experience on how our university, in close cooperation with the Department of Education of Madrid Community, is making the necessary adjustments to the learning, teaching and assessment of the Chinese, as "Chinese for Spanish Speakers", in accordance with the Common European Framework of Reference for Languages. Although we are focusing on the linguistic goals we will try to provide teachers of $\mathrm{CH} / \mathrm{LE}$ with simple theoretical and methodological clues and tips for them to use with their students, so that these students should be able not only to use the linguistic code (the phonetic, morphological, and syntactic level) but also to communicate appropriately in different contexts. Bringing into the classroom socio-cultural factors and non-verbal communication (paralinguistic, kinesic, proxemic, chronemic) implies working with integrated skills which will provide students with the necessary tools and strategies to be able to analyze, compare, contrast and reflect on the diverse realities. This awareness will avoid coming into prejudices and will develop positive attitudes to face the cultural and linguistic pluralism in this international and global society.
\end{abstract}

Keywords: Chinese, Spanish, linguistic competence, communicative competence, intercultural competence, linguistic objectives, the Framework, international society.

SUMARIO: 1. Introducción: nuevas y urgentes necesidades ante el auge del idioma chino en España. 2. El Marco y el proyecto general de política lingüística del Consejo de Europa. 3. Especificidad del chino mandarín: retos en su adaptación al Marco. 4. Objetivos y recursos lingüísticos en la enseñanza del "chino para hispanohablantes". 5. Integración de los recursos lingüísticos y los objetivos comunicativos. Autoevaluación. 6. Integración de la competencia lingüística con la competencia sociocultural y la comunicación no verbal. 7. Vínculos de interés para hispanohablantes que estudian chino. 8. Conclusiones. Referencias bibliográficas. 


\section{INTRODUCCIÓN: NUEVAS Y URGENTES NECESIDADES ANTE EL AUGE DEL IDIOMA CHINO EN ESPAÑA}

China ya no nos "suena a chino", pues cada vez está más cerca: la segunda economía mundial en términos de producto interior bruto y quinta potencia comercial, ha entrado en la Organización Mundial de Comercio (OMC), sus productos inundan los mercados europeos y americanos, el Premio Nobel de Literatura del año 2000 Gao Xingjian- es chino, las adopciones de niñas chinas han aumentado, las calles y colegios de toda España se llenan de inmigrantes chinos, son cada vez más los empresarios chinos que invierten en España y los empresarios españoles que invierten en China, donde se han celebrado los Juegos Olímpicos en el año 2008 (en Beijing) y la Exposición Universal en 2010 (en Shanghai).

El idioma chino está, pues, en auge. Más de 40 millones de personas en todo el mundo están estudiando chino y más de 2.600 universidades en 150 países ofrecen cursos de esta lengua. En España las universidades también han empezado a ofrecer estudios de grado y de posgrado; y los colegios, centros y academias donde se ofrece también chino crecen día a día. Se han creado, por tanto, nuevas y urgentes necesidades a las que hemos de hacer frente.

En este artículo vamos a exponer cómo en la Universidad Complutense, en estrecha colaboración con la Consejería de Educación de la Comunidad de Madrid, estamos reaccionando ante esta nueva situación. Hay una realidad que, aunque tiene sus detractores y sus puntos débiles, nos viene impuesta, que es la adaptación al llamado Marco Común Europeo de Referencia para las Lenguas: aprendizaje, enseñanza y evaluación, publicado por el Consejo de Europa, concretamente por el Departamento de Política Lingüística de Estrasburgo, en el año 2001 en inglés y en francés (título original: Common European Framework for Languages: Learning, Teaching, Assessment). En el año 2002 el Ministerio de Educación, junto con el Instituto Cervantes, la Junta de Castilla y León y la editorial Anaya lo tradujeron y publicaron en español. En Internet puede leerse en la dirección http://cvc.cervantes.es/obref/marco. Es el resultado de más de diez años de investigación exhaustiva llevada a cabo por un numeroso grupo de especialistas en Lingüística Aplicada. A partir de ahora hablaremos simplemente de Marco, para abreviar.

\section{EL MARCO Y EL PROYECTO GENERAL DE POLÍTICA LINGÜÍSTICA DEL CONSEJO DE EUROPA}

El Marco forma parte esencial del proyecto general de política lingüística del Consejo de Europa, que ha desarrollado un considerable esfuerzo por la unificación de directrices para la enseñanza y el aprendizaje de lenguas dentro del contexto europeo, esfuerzo que queda suficientemente avalado por proyectos que han marcado de forma significativa en las últimas décadas las líneas de trabajo de los profesionales de la enseñanza de lenguas en Europa, como son el desarrollo de las escalas 
descriptivas de niveles lingüísticos descritas en el Nivel Umbral, Nivel Plataforma (o Intermedio) y Nivel Avanzado, o informes y trabajos de orientación como Transparencia y coherencia en el aprendizaje de lenguas en Europa, Objetivos para el aprendizaje de lenguas extranjeras, etc.

Uno de los proyectos clave por su dimensión fue la celebración del llamado Año Europeo de la Lenguas, en el año 2001, que contó con un firme y comprometido apoyo de los países miembros y que se tradujo en la realización de más de 25.000 actividades; fue entonces cuando el Ministerio de Educación, Cultura y Deporte de España se comprometió a difundirlo en territorio español.

El objetivo del Marco es servir de "referencia" para la enseñanza, aprendizaje y evaluación de lenguas, por lo que será de utilidad no sólo para los profesores o docentes, sino también para los alumnos, examinadores, autores de manuales, formadores del profesorado, administradores educativos, etc. Se insiste en que, aparte de aportar conocimientos, destrezas y "consciencia" sobre el proceso de aprendizaje, es un medio de transmisión de valores, pues los individuos, y cito literalmente, serán "más independientes a la hora de pensar y actuar y, a la vez, más responsables y participativos... De esta forma, contribuye a fomentar la ciudadanía democrática" (Marco, XII).

A su vez, las referencias y niveles establecidos en el Marco, deberán constar en el denominado Europass, conjunto de documentos común en los 27 estados miembros de la Unión Europea, y cuya entrada en vigor fue aprobada en 2005 por el Parlamento Europeo, con la finalidad principal de facilitar la movilidad de estudiantes y trabajadores entre los distintos países gracias a la homogeneización de la información académica y laboral. Por tanto, para buscar empleo, ampliar la formación académica o realizar unas prácticas laborales en alguno de los países de la Unión Europea, será imprescindible presentar a la empresa o institución a la que se desea acceder tanto el curriculum como las credenciales académicas, profesionales y lingüísticas que certifiquen las capacidades del interesado. El actual sistema de titulaciones y formación difiere sustancialmente entre los estados miembros, lo que hace necesario un modelo común que facilite la comprensión de una manera clara y sencilla de la información necesaria para valorar la preparación de cualquier aspirante.

A modo de resumen, podemos decir que el Europass es un dossier compuesto por cinco documentos complementarios entre sí, de modo que cada persona crea o solicita aquellos que sean necesarios según sus objetivos profesionales o formativos. Entre éstos hay que distinguir, por una parte el Curriculum Vitae Europass y el Pasaporte de Lenguas Europass, que pueden elaborar directamente los interesados en las páginas del Centro Europeo para el Desarrollo de la Formación Profesional (Cedefop: http://europass.cedefop.europa.eu) y, por otra, los que deben ser expedidos por las diferentes administraciones: el Documento de Movilidad, el Suplemento Europass al Titulo / Certificado y el Suplemento Europass al Título Superior.

El Documento de Movilidad acredita la estancia de trabajo o estudios en otro país durante un periodo de tiempo determinado, ya sea por motivos académicos o profesionales, y recoge tanto las competencias o habilidades alcanzadas durante la estancia, como los certificados, títulos o calificaciones en el caso que los hubiera. A 
diferencia del Curriculum y el Pasaporte de Lenguas, este documento no puede ser elaborado personalmente, sino que requiere de la colaboración de las partes implicadas, tanto del centro de acogida como del de envío; este último es el que debe solicitar el documento de movilidad a través del CNE.

El Suplemento Europass al Titulo / Certificado es exclusivo para los titulados en Formación Profesional (FP) de grado medio o poseedores de un Certificado de Profesionalidad. En él se describen tanto los empleos para los que está capacitado el candidato, como las competencias adquiridas, el nivel de la titulación o el número de horas de formación. En el caso de los titulados en FP, el suplemento debe ser solicitado por la institución que expide el titulo a las diferentes consejerías de educación de las comunidades autónomas, mientras que el suplemento al certificado de profesionalidad es competencia del Servicio Público de Empleo Estatal (http://www.inem.es/inicial/inicio/index.html).

El Suplemento Europass al Título Superior está dirigido a los titulados en FP de Grado Superior y a titulados universitarios y sirve como complemento al título oficial; aporta información sobre la cualificación profesional que corresponde a la titulación, campos de estudio, duración oficial, requisitos de acceso, y detalle de todas las asignaturas cursadas con las horas lectivas dedicadas y la nota adquirida; asimismo, se incluye información sobre el sistema nacional de enseñanza superior y el sistema de calificaciones. En el caso de los titulados universitarios, el suplemento Europass es expedido por las universidades coordinadas por el Consejo de Coordinación Universitaria y, en el caso de titulados de FP de grado superior, la solicitud y expedición del documento corresponde a las instituciones que expiden los títulos según las normas de cada comunidad autónoma.

De esos cinco documentos, los que más nos interesan son los dos primeros que hemos mencionado: el Curriculum Vitae Europass y el Portfolio de Lenguas Europass. Los impresos se pueden descargar directamente de Internet, donde además se ofrecen modelos a modo de ejemplo): el Curriculum Vitae Europass en http://www.mec.es/europass y el Portfolio de Lenguas Europass en http://www.mec.es/programas-europeos y http://www.coe.int/portfolio .

El Portfolio pretende informar de forma clara sobre el nivel de competencia lingüística del alumno y de sus experiencias importantes a lo largo de su aprendizaje de la lengua; no reemplaza a los certificados y diplomas tradicionales, sino que sirve como complemento de los mismos. El Portfolio consta de tres partes:

a- Pasaporte Lingüístico Europass (http://europass.cedefop.eu.int-), que es una manera sencilla de resumir las habilidades en las distintas competencias lingüísticas (hablar, leer, escribir y escuchar), utilizando los seis niveles europeos del Marco: usuario básico (A1 y A2), usuario independiente (B1 y B2) y usuario competente (C1 y $\mathrm{C} 2$ ).

b- Biografía Lingüística, en la que se describen las experiencias del titular en cada una de las lenguas y está diseñada para servir de guía al aprendiz a la hora de planificar y evaluar su progreso. 
c- El Dossier, que contiene ejemplos de trabajos personales para ilustrar las capacidades y conocimientos lingüísticos (redacciones, proyectos, grabaciones en audio, vídeo, presentaciones, etc.)

\section{ESPECIFICIDAD DEL CHINO MANDARÍN: RETOS EN SU ADAPTACIÓN AL MARCO}

En un principio el Marco se pensó, claro está, para las lenguas europeas, pero con el tiempo se está aplicando también a todas las demás, aunque se encuentren muy alejadas geográfica y tipológicamente (así, en la UCM se está haciendo con el chino, el japonés, el hindi, el swahili, el turco, el yiddish, etc). En el caso del chino, nosotras estamos trabajando con la Consejería de Educación de la CAM y con el CSIM (Centro Superior de Idiomas Modernos) de la UCM. Hemos de reconocer que a veces esto lo estamos llevando a cabo de un forma un tanto "artificial", intentando de alguna manera "forzar" el chino para ajustarlo a un "ideal", a unos moldes que, insistimos, nos vienen impuestos, por mucho que el Dpto. de Política Lingüística del Consejo de Europa diga que se trata tan sólo de una "referencia"; así, por citar tan sólo un ejemplo, es evidente que en chino, debido a su escritura no alfabética sino a través de caracteres, siempre habrá un desfase o descompensación entre la expresión, comprensión e interacción oral, por una parte, y la comprensión lectora y expresión escrita, por otra, ya sea en un sentido o en otro: así, es posible que tengamos alumnos que nunca han ido a China y que reconocen y escriben bastante bien los caracteres aprendidos, pero que tienen dificultades con los fonemas y los tonos, tanto para expresarse ellos mismos como para comprender; justo al contrario de los alumnos que, tras estudiar en España, han practicado durante unos meses, un año o más tiempo en China; además, en nuestras clases nos encontramos cada vez con más alumnos chinos que hablan perfectamente pero que no saben leer ni escribir, a veces ni siquiera su nombre. Aún así, y pese a reconocer la enorme complejidad que entraña el llevar a la práctica este ambicioso proyecto del Marco Europeo, y pese también a prever que numerosos aspectos concretos deberán ir perfeccionándose a través de la experiencia que da los años, creemos que el espíritu de tender puentes y de facilitar la movilidad y los contactos entre distintos países es positivo.

\section{OBJETIVOS Y RECURSOS LINGÜÍSTICOS EN LA ENSEÑANZA DEL "CHINO PARA HISPANOHABLANTES"}

En la UCM, como sucede en general en España y en el resto de los países europeos, estamos todavía en una fase "intermedia baja", pues acabamos de elaborar los RECURSOS LINGÜÍSTICOS necesarios para llevar a cabo las actividades y funciones comunicativas de cada nivel del Marco. Los de los niveles Inicial $1 \mathrm{e}$ Inicial 2 (que se corresponden con los niveles A1 y el A2 del MCER) los elaboró el profesor y jefe del Dpto. de chino de la EOI de Madrid, D. Li Wan-Tang; nosotras 
hemos elaborado los del nivel Intermedio 1 e Intermedio 2, equivalentes al nivel B1 del MCER (publicados en el BOCAM del 22 de junio de 2007) y los del nivel avanzado 1 y 2, equivalentes al B2 del MCER (publicados en el BOCAM del 30 de julio de 2008). Vamos a comentar cómo hemos realizado esta labor, que es la que conocemos y en la que seguimos trabajando.

En primer lugar, es fundamental tener en cuenta las capacidades que se han de conseguir en cada nivel del proceso de aprendizaje en lo referente a las cinco destrezas: comprensión auditiva, comprensión lectora, expresión oral, expresión escrita e interación oral.

Veamos un resumen de lo que se pretende en cada nivel del Marco:

\begin{tabular}{|c|c|c|c|c|}
\hline & & $A 1$ & $A 2$ & $B 1$ \\
\hline \multirow{2}{*}{$\begin{array}{l}C \\
O \\
M \\
P \\
R \\
E \\
N \\
D \\
E \\
R\end{array}$} & $\begin{array}{l}\text { Comprensión } \\
\text { auditiva }\end{array}$ & $\begin{array}{l}\text { Reconozco palabras y } \\
\text { expresiones muy básicas que se } \\
\text { usan habitualmente, relativas a mí } \\
\text { mismo, a mi familia y a mi entorno } \\
\text { inmediato cuando se habla } \\
\text { despacio y con claridad. }\end{array}$ & $\begin{array}{l}\text { Comprendo frases y el vocabulario } \\
\text { más habitual sobre temas de } \\
\text { interés personal (información } \\
\text { personal y familiar muy básica, } \\
\text { compras, lugar de residencia, } \\
\text { empleo). }\end{array}$ & $\begin{array}{l}\text { Comprendo las ideas principales } \\
\text { cuando el discurso es claro y } \\
\text { normal y se tratan asuntos } \\
\text { cotidianos que tienen lugar en el } \\
\text { trabajo, en la escuela, durante el } \\
\text { tiempo de ocio, etc. Comprendo } \\
\text { la idea principal de muchos } \\
\text { programas de radio o televisión } \\
\text { que tratan temas actuales o } \\
\text { asuntos de interés personal o } \\
\text { profesional, cuando la } \\
\text { articulación es relativamente } \\
\text { lenta y clara. }\end{array}$ \\
\hline & $\begin{array}{l}\text { Comprensión } \\
\text { lectora }\end{array}$ & $\begin{array}{l}\text { Comprendo palabras y nombres } \\
\text { conocidos y frases muy sencillas, } \\
\text { por ejemplo las que hay en } \\
\text { letreros, carteles y catálogos. }\end{array}$ & $\begin{array}{l}\text { Soy capaz de leer textos muy } \\
\text { breves y sencillos. Sé encontrar } \\
\text { información específica y predecible } \\
\text { en escritos sencillos y cotidianos } \\
\text { como anuncios publicitarios, } \\
\text { prospectos, menús y horarios y } \\
\text { comprendo cartas personales } \\
\text { breves y sencillas. }\end{array}$ & $\begin{array}{l}\text { Comprendo textos redactados } \\
\text { en una lengua de uso habitual y } \\
\text { cotidiano o relacionada con el } \\
\text { trabajo. Comprendo la } \\
\text { descripción de acontecimientos, } \\
\text { sentimientos y deseos en cartas } \\
\text { personales. }\end{array}$ \\
\hline \multirow[t]{2}{*}{$\begin{array}{l}H \\
A \\
B \\
L \\
A \\
R\end{array}$} & $\begin{array}{l}\text { Interacción } \\
\text { oral }\end{array}$ & $\begin{array}{l}\text { Puedo participar en una } \\
\text { conversación de forma sencilla } \\
\text { siempre que la otra persona esté } \\
\text { dispuesta a repetir lo que ha } \\
\text { dicho o a decirlo con otras } \\
\text { palabras y a una velocidad más } \\
\text { lenta y me ayude a formular lo } \\
\text { que intento decir. Planteo y } \\
\text { contesto preguntas sencillas } \\
\text { sobre temas de necesidad } \\
\text { inmediata o asuntos muy } \\
\text { habituales. }\end{array}$ & $\begin{array}{l}\text { Puedo comunicarme en tareas } \\
\text { sencillas y habituales que } \\
\text { requieren un intercambio simple y } \\
\text { directo de información sobre } \\
\text { actividades y asuntos cotidianos. } \\
\text { Soy capaz de realizar intercambios } \\
\text { sociales muy breves, aunque, por } \\
\text { lo general, no puedo comprender } \\
\text { lo suficiente como para mantener } \\
\text { la conversación por mí mismo. }\end{array}$ & $\begin{array}{l}\text { Sé desenvolverme en casi todas } \\
\text { las situaciones que se me } \\
\text { presentan cuando viajo donde } \\
\text { se habla esa lengua. Puedo } \\
\text { participar espontáneamente en } \\
\text { una conversación que trate } \\
\text { temas cotidianos de interés } \\
\text { personal o que sean pertinentes } \\
\text { para la vida diaria (por ejemplo, } \\
\text { familia, aficiones, trabajo, viajes } \\
\text { y acontecimientos actuales). }\end{array}$ \\
\hline & $\begin{array}{l}\text { Expresión } \\
\text { oral }\end{array}$ & $\begin{array}{l}\text { Utilizo expresiones y frases } \\
\text { sencillas para describir el lugar } \\
\text { donde vivo y las personas que } \\
\text { conozco. }\end{array}$ & $\begin{array}{l}\text { Utilizo una serie de expresiones y } \\
\text { frases para describir con términos } \\
\text { sencillos a mi familia y otras } \\
\text { personas, mis condiciones de vida, } \\
\text { mi origen educativo y mi trabajo } \\
\text { actual o el último que tuve. }\end{array}$ & $\begin{array}{l}\text { Sé enlazar frases de forma } \\
\text { sencilla con el fin de describir } \\
\text { experiencias y hechos, mis } \\
\text { sueños, esperanzas y } \\
\text { ambiciones. }\end{array}$ \\
\hline
\end{tabular}




\begin{tabular}{|l|l|l|l|l|}
\hline E & Escribir & Soy capaz de escribir postales & Soy capaz de escribir notas y & Soy capaz de escribir textos \\
S & cortas y sencillas, por ejemplo & mensajes breves y sencillos & sencillos y bien enlazados sobre \\
C & para enviar felicitaciones. Sé & relativos a mis necesidades & inas me son conocidos o \\
R & rellenar formularios con datos & inmediatas. Puedo escribir cartas & de interés personal. Puedo \\
I & personales, por ejemplo mi & personales muy sencillas, por & escribir cartas personales que \\
B & nombre, mi nacionalidad y mi & ejemplo agradeciendo algo a & describen experiencias e \\
Impresiones. \\
I
\end{tabular}

\begin{tabular}{|c|c|c|c|c|}
\hline & & B2 & C1 & $\mathrm{C} 2$ \\
\hline \multirow{2}{*}{$\begin{array}{l}C \\
O \\
M \\
P \\
R \\
E \\
N \\
D \\
E \\
R\end{array}$} & $\begin{array}{l}\text { Comprensión } \\
\text { auditiva }\end{array}$ & $\begin{array}{l}\text { Comprendo discursos y } \\
\text { conferencias extensos e incluso } \\
\text { sigo líneas argumentales } \\
\text { complejas siempre que el tema } \\
\text { sea relativamente conocido. } \\
\text { Comprendo casi todas las noticias } \\
\text { de la televisión y los programas } \\
\text { sobre temas actuales. }\end{array}$ & $\begin{array}{l}\text { Comprendo discursos extensos } \\
\text { incluso cuando no están } \\
\text { estructurados con claridad y } \\
\text { cuando las relaciones están sólo } \\
\text { implícitas y no se señalan } \\
\text { explícitamente. Comprendo sin } \\
\text { mucho esfuerzo los programas de } \\
\text { televisión y las películas. }\end{array}$ & $\begin{array}{l}\text { No tengo ninguna dificultad para } \\
\text { comprender cualquier tipo de } \\
\text { lengua hablada, tanto en } \\
\text { conversaciones en vivo como en } \\
\text { discursos retransmitidos, aunque } \\
\text { se produzcan a una velocidad de } \\
\text { hablante nativo, siempre que } \\
\text { tenga tiempo para familiarizarme } \\
\text { con él }\end{array}$ \\
\hline & $\begin{array}{l}\text { Comprensión } \\
\text { de lectura }\end{array}$ & $\begin{array}{l}\text { Soy capaz de leer artículos e } \\
\text { informes relativos a problemas } \\
\text { contemporáneos en los que los } \\
\text { autores adoptan posturas o puntos } \\
\text { de vista concretos. Comprendo la } \\
\text { prosa literaria contemporánea. }\end{array}$ & $\begin{array}{l}\text { Comprendo textos largos y } \\
\text { complejos de carácter literario o } \\
\text { basados en hechos, apreciando } \\
\text { distinciones de estilo. }\end{array}$ & $\begin{array}{l}\text { Soy capaz de leer con facilidad } \\
\text { prácticamente todas las formas } \\
\text { de lengua escrita, incluyendo } \\
\text { textos abstractos estructural o } \\
\text { lingüísticamente complejos como, } \\
\text { por ejemplo, manuales, artículos } \\
\text { especializados y obras literarias. }\end{array}$ \\
\hline $\begin{array}{l}\mathrm{H} \\
\mathrm{A} \\
\mathrm{B}\end{array}$ & $\begin{array}{l}\text { Interacción } \\
\text { oral }\end{array}$ & $\begin{array}{l}\text { Puedo participar en una } \\
\text { conversación con cierta fluidez y } \\
\text { espontaneidad, lo que posibilita la } \\
\text { comunicación normal con } \\
\text { hablantes nativos. Puedo tomar } \\
\text { parte activa en debates } \\
\text { desarrollados en situaciones } \\
\text { cotidianas explicando y } \\
\text { defendiendo mis puntos de vista. }\end{array}$ & $\begin{array}{l}\text { Me expreso con fluidez y } \\
\text { espontaneidad sin tener que } \\
\text { buscar de forma muy evidente las } \\
\text { expresiones adecuadas. Utilizo el } \\
\text { lenguaje con flexibilidad y eficacia } \\
\text { para fines sociales y profesionales. }\end{array}$ & $\begin{array}{l}\text { Tomo parte sin esfuerzo en } \\
\text { cualquier conversación o debate y } \\
\text { conozco bien modismos, frases } \\
\text { hechas y expresiones coloquiales. } \\
\text { Me expreso con fluidez y } \\
\text { transmito matices sutiles de } \\
\text { sentido con precisión. Si tengo un } \\
\text { problema, sorteo la dificultad con } \\
\text { tanta discreción que los demás } \\
\text { apenas se dan cuenta. }\end{array}$ \\
\hline $\mathrm{R}$ & $\begin{array}{l}\text { Expresión } \\
\text { oral }\end{array}$ & $\begin{array}{l}\text { Presento descripciones claras y } \\
\text { detalladas de una amplia serie de } \\
\text { temas relacionados con mi } \\
\text { especialidad. }\end{array}$ & $\begin{array}{l}\text { Presento descripciones claras y } \\
\text { detalladas sobre temas complejos } \\
\text { que incluyen otros temas, } \\
\text { desarrollando ideas concretas y } \\
\text { terminando con una conclusión } \\
\text { apropiada. }\end{array}$ & $\begin{array}{l}\text { Presento descripciones o } \\
\text { argumentos de forma clara y } \\
\text { fluida y con un estilo que es } \\
\text { adecuado al contexto y con una } \\
\text { estructura lógica y eficaz que } \\
\text { ayuda al oyente a fijarse en las } \\
\text { ideas importantes y a recordarlas. }\end{array}$ \\
\hline
\end{tabular}




\begin{tabular}{|c|c|c|c|c|}
\hline $\begin{array}{l}\text { E } \\
\text { S } \\
\text { C } \\
\text { R } \\
\text { I } \\
\text { B } \\
\text { I } \\
\text { R }\end{array}$ & Escribir & $\begin{array}{l}\text { Soy capaz de escribir textos claros } \\
\text { y detallados sobre una amplia } \\
\text { serie de temas relacionados con } \\
\text { mis intereses. Puedo escribir } \\
\text { redacciones o informes } \\
\text { transmitiendo información o } \\
\text { proponiendo motivos que apoyen } \\
\text { o refuten un punto de vista } \\
\text { concreto. Sé escribir cartas que } \\
\text { destacan la importancia que le doy } \\
\text { a determinados hechos y } \\
\text { experiencias. }\end{array}$ & $\begin{array}{l}\text { Soy capaz de expresarme en } \\
\text { textos claros y bien estructurados } \\
\text { exponiendo puntos de vista con } \\
\text { cierta extensión. Puedo escribir } \\
\text { sobre temas complejos en cartas, } \\
\text { redacciones o informes resaltando } \\
\text { lo que considero que son aspectos } \\
\text { importantes. Selecciono el estilo } \\
\text { apropiado para los lectores a los } \\
\text { que van dirigidos mis escritos. }\end{array}$ & $\begin{array}{l}\text { Soy capaz de escribir textos } \\
\text { claros y fluidos en un estilo } \\
\text { apropiado. Puedo escribir cartas, } \\
\text { informes o artículos complejos } \\
\text { que presentan argumentos con } \\
\text { una estructura lógica y eficaz que } \\
\text { ayuda al oyente a fijarse en las } \\
\text { ideas importantes y a recordarlas. } \\
\text { Escribo resúmenes y reseñas de } \\
\text { obras profesionales o literarias. }\end{array}$ \\
\hline
\end{tabular}

(MCER, Consejo de Europa 2002: 30-31)

Basándonos en ese cuadro de referencia, establecimos una serie de puntos clave o de énfasis para cada nivel dentro del proceso de aprendizaje, y después intentamos encajarlos en el vocabulario y situaciones comunicativas más frecuentes. El resultado fue el que veremos a continuación. Y aquí, queremos dejar constancia de que la terminología, el orden y la estructuración de contenidos no son personales, sino que la Consejería de Educación los elaboró para todos los idiomas por igual. Existen 4 grandes apartados: oración, discurso, léxico y semántica (entendida como una disciplina transversal), y fonología y ortografía. Nótese además, que algunas categorías aparecen recogidas, aunque desde diferentes puntos de vista, en varios apartados y/o secciones: así, p.ej., es lógico que algunas conjunciones aparezcan tanto en la "oración compleja", como en "enlaces" y en "cohesión y organización del discurso". Para que se entienda, pondremos como ejemplo los objetivos lingüísticos que hemos establecido para el nivel intermedio 2 y avanzado 2 (recuérdese que nos estamos refiriendo siempre a la enseñanza del "chino para hispanohablantes", lo que supone un estudio contrastivo previo de ambas lenguas).

\section{OBJETIVOS LINGÜÍSTICOS del Nivel Intermedio 2 (B1 del Marco). CHINO}

Uso contextualizado de los recursos programados en el Nivel Básico (A1 y A2) y de los que se listan a continuación, para llevar a cabo las actividades y funciones comunicativas del nivel B1. En todo este apartado se consolidarán y ampliarán los conocimientos anteriores aplicados a la lengua estándar. Se recogen y amplían los contenidos del nivel intermedio 1 y se destacan con un (2) los apartados con aspectos nuevos).

\section{ORACION}

\subsection{Oración simple}

- Consolidación y refuerzo de la actitud del hablante y modalidades de oración: modalidad enunciativa, interrogativa, imperativa, exclamativa, desiderativa y 
dubitativa ( + afirmativas, negativas y enfáticas); casos especiales en las alteraciones del orden y elipsis de elementos. Entonación de los casos anteriores

- Orden de los elementos en cada tipo de oración: sujeto, predicado, circunstantes oracionales: 句子结构

- Refuerzo de las oraciones impersonales (有/ 是, 刮风了, 安静, 活到老学至㧯). Otros usos de有y是

- Oraciones activas con 把 Formación, requisitos y usos. SUJ + (NEG)+ AUX + 把

- Oraciones pasivas con被, 叫给y让 Formación, requisitos y usos: SN1 + (NEG) 被 SN2 (gěi) V-... (永原常常被他老㠼号了).

- Oraciones con la construcción 是..的 Requisitos, funciones y usos (你是怎么来的? $\rightarrow$ 我是坐 (机来的). Repercusiones de la alteración del orden: SUJ (+NEG) + 是..+ $\mathrm{V}$ 的; SUJ是 $+\mathrm{V}-\mathrm{CD}+$ 的 SUJ是 $+\mathrm{V}$ 的 $+\mathrm{CD}$ (我们不是九点神开门的 我们不是九点钟开的了.

(2) Usos de la pasiva del chino frente a los de la pasiva en español o en inglés. Diferencias con la construcción是..的 Casos problemáticos: enfatización del agente cuando el tópico es el CD (*那副画被黎太太画了/ 那湢田是黎太太画的)

\section{2- Oración compleja}

- Coordinación afirmativa y negativa. Refuerzo y usos especiales de la coordinación copulativa又..又 也..也一方面..一方面 并且 / 而且，不但..也 disyuntiva 还是 或是y adversativa 但是, 不过, 然而, 倒是

- Subordinación adjetiva (o de relativo): especificativa (P.Rel.+ 的+N. [Prop. Adjetiva Especificativa的] $+\mathrm{N}$ ) frente a explicativa (N, [Prop. Adjetiva Explicativa]的], $+\mathrm{N})$.

- Cambio en el orden de los deteminantes (posesivos, demostrativos, indefinidos y numerales) respecto a la proposición de relativo y al nombre núcleo

(这三个戴相镜学学生都很用功/ 戴期境食文二个学生都很用功).

. Utilización de 所delante del verbo en las proposiciones adjetivas sin consecuente expreso y en función de atributo (你的帮阻力是我所需要的).

. Eliminación del nombre núcleo en la subordinación adjetiva de carácter genérico (大卫是最需要我们笊助的 (人).

- Oraciones de "Verbos en Serie" (para expresar la subordinación nominal o completiva del español): 你拮电话很方便, 我文団要我学英文, 他命令你扫也, 我买一串项琏很直钱 他写信抽烟

- Subordinación adverbial (o circunstancial). Consolidación y refuerzo de los nexos:

- Subordinación adverbial temporal 1: -的猴 -以前y -以后.

Subordinación adverbial temporal 2: 一边.. 一边, 一... 就y V-了... 就

- Subordinación adverbial condicional 1: 要是, 如果 假如 假吏.. 就(也).

Subordinación adverbial condicional 2:

只要..就 除非, 要不是..就 不是..就是..要不然就是, 只有...才.

- Subordinación causal-consecutiva: 因为/由于... 所以/ 就 因为...的关系.. 所以/就 
- Subordinación concesiva: 虽然.. 倒/ 可是/还是 就是... 还 无论... 都/也

- Subordinación final: 为的是 省得 是为了... 才... 的

\section{3- GRUPO DEL NOMBRE}

- Funciones del grupo del nombre. Partículas o marcas de esas funciones.

1.3.1- Nombre

- Clases de nombres.

- Formas léxicas de indicar el concepto de género.

- Formas de indicar el concepto de plural: - 们, 都, 几, 些。

1.3.2- Determinantes

- Posesivos. Usos de 我的, 你的, 他的. Condiciones para la eliminación de la partícula 的 (我爸爸).

- Demostrativos. Usos de 这 y 那.

(2) Indefinidos 1. Usos de 几, 些 $\mathrm{y}$ 每. Indefinidos 2. Usos de整 y某一.

- Numerales. Formas y usos especiales. Insistencia en 二, 两 (我写了两封信了), 俩 (我们俩), 零 (七万(零)五百零五) y en los cardinales con el prefijo 第 (第一次). Gestos de los números y sistema monetario: Det. Num.+ Clas. 块 / 毛/分 + 钱. Años, matrículas y teléfonos

- Interrogativos. Usos de 什么, 几 y 多少.

(2Uso interrogativo e indefinido (疑可助词及不定词) de 谁, 什么, 怎么, 怎么样, 为什么多少 / 几+Clas., 哪儿哪里, 哪 + Clas., 干公y 什么时候

- Combinatoria y posición de los determinantes respecto a los clasificadores (o palabras medidoras) y al nombre núcleo: 你(的)那两位外国朋友.

- Marca cero: anteposición verbal (determinación贼 跑了) frente a posposición (indeterminación跑了贼). Equivalencia en español: artículo determinado / indeterminado (el ladrón / un ladrón). Otros valores y casos especiales.

\subsection{3- Clasificadores o palabras medidoras}

- Consolidación y refuerzo de usos de los clasificadores individuales: 把本条只张 枚 所, 位匹件, 口, 个.

- Consolidación y refuerzo de usos de los clasificadores colectivos: 对。双 打, 十, 千, 行, 套副帮连流

- Consolidación y refuerzo de usos de los clasificadores partitivos: 份部块团, 半, 把 栏片, 段点络轴

- Consolidación y refuerzo de usos de los clasificadores transitorios: 包, 袋瓶罐碗, 杯, 篮抽居 盒箱书架

- Consolidación y refuerzo de usos de los clasificadores estándar: 公分, 公寸, 公里, 斤, 克本点刻, 分, 秒, 毛天年.

- Combinatoria de un mismo nombre con distintos clasificadores: Det. + Clas. + N

(一张支票/一本支票一根筷子/ 一双筷子/一把筷子).

\subsection{4- Complementos del nombre}

- Adjetivos (invariables). Clases y combinatoria con 的 (好人 / 很好的人). 
- Posición (antepuestos al nombre y especificativos). Diferencias con los verbos estativos de cualidad (好人 / 人好).

- Modificadores del adjetivo (比较高, 那么高, 对我很好)

(2) Grados del adjetivo 1. Utilización de 很-, 太-, 更-, 比较-, 最- .

Grados del adjetivo 2. Utilización de -极了, - 死了, 挺-...-的, -的不得了.

- Otras formas de complementos del nombre (delante del nombre-núcleo): nombre en aposición (黄河, 黎部长) y oración adjetiva $\mathrm{o}$ de relativo (我们想买的那个房子在乡下).

\subsection{5- Pronombres}

- Formas, funciones, posición, combinatoria, uso / omisión.

- Personales: funciones, formas, combinatoria y colocación.

- Formas de tratamiento habituales (你/您).

(2) Importancia de la ausencia de pronombre personal (我ø买了ø, frente al español $\underline{s e}$ la compré).

(2) Obligatoriedad del pronombre personal con el marcador activo把 y el pasivo被.

- Pronombres posesivos, demostrativos, indefinidos y numerales.

- Pronombres interrogativos: 谁, 什么 $+\varnothing$, 哪 + 个 $+\varnothing$, 几 + 个 $+\varnothing$, 多少 $+\varnothing$.

Relación entre los pronombres interrogativos e indefinidos.

- Pronombre relativo 的.

- Pronombre reflexivo 自己。

\section{4- GRUPO DEL VERBO}

- Núcleo -verbo- y complementos de acuerdo con el tipo de verbo.

\subsection{1- Verbo}

- Propiedades del verbo.

- Consolidación y refuerzo de las clases de verbos.

- Maneras de expresar el concepto de tiempo: presente, pasado, futuro y habitualidad. Usos especiales.

- Valores aspectuales: perfectivo - $了$, imperfectivo progresivo在-, 正在-, 正在....呢, imperfectivo durativo -着,perfecto experiencial -过1, perfecto reciente -过2, incoativo -起来, continuativo -下去.

(2) Clases y usos de los verbos resultativos gramaticales 到, 见起了, 好 (这只手表太贵, 我买不起 y léxicos (推开, 穿破, 撕卒, 打坏, 撞开). Su combinación con los potenciales 得y不 (推得开 / 学不了).

- Verbos direccionales simples去 来 上下, 走 到在(拿出来). Su combinación con los potenciales 得y不 (拿得来/搬不去).

(2) Verbos direccionales compuestos (搬井㕕). Su combinación con los potenciales 得不(拿得下来/ 搬不上去).

- Valores de los verbos reduplicados (看看, 检查检查). Usos especiales.

- Valores modales a través de verbos auxiliares: 会 能可以 要, 得, 应亥, 必须

- Formas de expresar el imperativo: 不要y 别 Suavización a través de partículas modales (吧). 
- Perífrasis verbales de uso frecuente (喜欢游永 想去).

- Verbos transitivos.- matices de las 4 posiciones del CD: a- (Suj) + V+ CD (学生已经故完功课). b- (Suj) + CD + V (学生功课已经故完了). c- (Suj) + 把CD + V (小孩把茶杯打破了). d- CD $+\mathrm{Suj}+\mathrm{V}$ (黄车子我很喜欢).

- Verbos que exigen CD y CI: 给送还付.

(2) Diferentes usos de 是y de 有.

(2) Los verbos auxiliares, los verbos de estado y los verbos adjetivales (o de cualidad). Su comportamiento con la negación y con los sufijos aspectuales.

- Los clasificadores verbales 次边回y 趟

- Voz activa con 把 Formación, requisitos y usos. SUJ + (NEG)+ AUX + 把C.DIR ( 给 $+\mathrm{V}$...: 我不要把这些理还关合你 Combinación con la negación y con los verbos auxiliares.

- Voz pasiva con被叫给y 让, Formación, requisitos y usos: SN1 + (NEG) 被 SN2 (给) V-... (永原常常被也老师骂了). Combinación con la negación y con los verbos auxiliares.

(2)Usos de la pasiva del chino frente a los de la pasiva en español o en inglés. Diferencias con la construcción是..的 Casos problemáticos: enfatización del agente cuando el tópico es el CD (*那湢画被黎太太画了/ 那湢画是黎太太画的)

\section{5- ADVERBIO Y LOCUCIONES ADVERBIALES}

- Adverbios y locuciones adverbiales de tiempo: 早, 晚, 以后, 以前, 现在, 再, 再一次 已经，还 昨天, 前天 马上，那时，那么，永远 有时候 常常, 有一次 今天 明天 后天

- Adverbios y locuciones adverbiales de lugar: 这里这儿, 那里, 那儿, 旁边 周围, 对面 到处.. 都前面, 前边 后面, 上面 上边 后边, 下面 下边 里面 里头, 外面, 外边.

- Adverbios y locuciones adverbiales de modo con la partícula 地. Casos de reduplicación: 好好儿地, 慢慢地, 快快地, 快快乐乐地, 安安静静地, 舒舒服服地.... Adverbios de modo onomatopéyicos (叮当叮当地).

- Posición respecto al verbo y al sujeto: adverbios de tiempo y actitud / adverbios de modo. Posición preverbal / posverbal de los adverbios de tiempo: puntualidad / duración (我三点钟吃饭 / 我吃了三个小时的反). Adverbios móviles (将来，昨天) frente a adverbios fijos (只, 就, 才/就).

- Adverbios de cantidad o de medida (几乎, 很 很多, 恨少, 太 绝下... ) modificando a diferentes categorías -很累, 很多朋友, 开得很快- y a otro adverbio-很远- ). Usos de 一点儿 y 有一点儿. Gradación del adverbio.

- Adverbios interrogativos: 哪儿，什么时候，怎么，怎么样，什么时候，为什么 Posición en la oración. Calcos y errores frecuentes.

- Refuerzo y ampliación de los adverbios de afirmación, negación y duda: 是, 对, 真 不, 没 从不, 从未 也不, 也没, 完全不, 也许, 或许.

- Adverbios negativos y su interación con otros adverbios.

El adverbio 刚y el sustantivo de tiempo 刚才. 


\section{6- PARTÍCULAS}

- Consolidación y refuerzo de las clases de partículas y de su posición en la frase.

- Usos de la partícula 的: posesión (我的电脑), relativo (我租的房子), pronominalización (红色的), construcción 是...的 (他是坐飞机来的), etc.

(2) Partícula de grado 得. Su negación.

(2)Partícula modal oracional 了 frente a sufijo verbal perfectivo了: (已经) $\mathrm{O}+了 / \mathrm{V}$ + 了... (我买两本书了/我买了两本书).

Repercusiones en la negación: 还没 (有) $+V \ldots$ 呢 / 没 $+V+\varnothing \ldots$ (我还没买书呢 / 我没买书)

- Las partículas modales oracionales.- Formas y usos (cambio de situación, decisión tajante, certidumbre, énfasis, extrañeza, reafirmación, suposición, aprobación, contrariedad, suavización de órdenes, familiaridad y cortesía):了, 的, 呢, 吗, 嘛, 吧, 哦，啊，呀，哇，啦 (他不喝䣵睡觉泡巴 你还没它奴尼?

\section{7- ENLACES}

\subsection{1- Preposiciones y posposiciones}

- Preposiciones (coverbos). Características y posición.

- Posición en la oración: "Sujeto y / o tópico $+[\mathrm{CoV} .-\mathrm{SN}]+\mathrm{V}$ " (上月我替张老市上课 黎青昨天到乡下去了)

(2)Usos de 给, 从, 在, 跟, 坐, 用, 替, 离, 像, 叫. Usos de 除了, 按, 沿, 关于.

- Posposiciones (SN+part. locativa -posposición-): consolidación y ampliación.

- Posición: SN+part. locativa (posposición) (他们把这些书西放在桌子底下)

- Usos de 上, 下, 里, 前面, 后面, 对面, 右边, 左边, 旁边, 附近.

Presencia / ausencia de 面, 边, 头.

1.7.2- Conjunciones y locuciones conjuntivas

- Coordinantes copulativos: 并且, 而且, 不但...也还, 不但...连...也/都, 又... 又, 一方面... 一方面, 越...越.

- Coordinantes disyuntivos: 还是, 或是, 或者是.

(2) Coordinantes adversativos 1: 可是, 但是, 不过.

Coordinantes adversativos 2 : 然而, 倒是.

- Subordinantes para relacionar la frase subordinada con la principal:

- Subordinantes temporales de uso habitual: -的时候, 以前, 以后.

(2) Subordinantes condicionales e hipotéticos 1: 如果 / 假如 / 要是 / 假使... 就/也.

Subordinantes condicionales e hipotéticos 2: 只要... (就),

除非,要不是...就, 不是...就是...要不然就是, 只有...才; -的话...就.

- Subordinantes causales-consecutivos: 因为 / 由于/因为的矢系...所以/就

(2) Subordinantes concesivos 1: 虽然...倒/可是/ 还是

Subordinantes concesivos 2: 即使/ 就是..也/ 还 无论/ 不管...都/也 
(2) Subordinantes finales 1: 为了.

Subordinantes finales 2: 为的是 省得, 是为了...才而..的

- Subordinantes comparativos: de igualdad ( $\mathrm{A}$ 跟 $\mathrm{B}$ 一样 $+\mathrm{V}$ ), de superioridad (A 比B

$+\mathrm{V})$ y de inferioridad (A 沒有-B 那么 $+\mathrm{V}, \mathrm{A}$ 不如B那么 $+\mathrm{V}$ ).

\section{2- DISCURSO}

2.1- Cohesión

- Procedimientos para mantener el tema:

. Repeticiones (intencionadas) (李先生人很子).

. Recursos de sustitución sencillos con referente claro: elipsis, pronombres y adverbios o expresiones con valor anafórico

(那个, 那一年, 那儿, 一样的地方, 那牪事情, 那个分题.

. Por procedimientos léxicos: sinónimos, hiperónimos de vocabulario frecuente (电脑 $>$ 机器), a través de uno de los términos que entran en la definición (引浔, 政治家 的总统, y a través de la nominalización (我每天运动/ 我做的运动..).

. Posición preverbal para los nombres ya presentados (贼跑了 frente a 跑了贼.

- Coherencia de la temporalidad verbal en el discurso (那个时候。

- Conectores 1: 又..又 也..也一方面..一方面 并且 /而且 不但..也 (还), 因为, 所以 的猴 另外, 比如 只要..就 除非, 要不是..就 不是..就是..要不然就是 只有...才.

- Conectores 2:

因为/ 由于... 所以/就 因为的矢系.. 所以/就, 虽然.. 倒/可是/还是 就是... 还 无论... 都/也为的是 省得, 是为了... 才... 的

(2)Estudio detallado de algunos conectores aditivos: 除了.......外

(他除了懂西班玡语之外, 还董又语)

(2)Estudio detallado de algunos conectores consecutivos: 因此

(她很用功读中状此考了第一名)

(2) Estudio detallado de algunos conectores contraargumentativos: 换句话说

（这件事很重要，换向话说你得认真地去做

(2)Estudio detallado de algunos conectores justificativos: 既然

(既然你已知道了, 我就没必要告诉你

\section{2- Organización}

- Marcadores de iniciación: fórmulas de saludo, presentación, introducción del tema: 请问，劳驾，麻烦你，对不起，不好意思，首先(开会之前，我门首先请王先生讲话)

- Marcadores de estructuración: ordenadores (de apertura, de continuación y de cierre) comentadores, digresores: 那么，首先 顺更 (开会之前，我们首先请王先生讲话 顺更可一下，你今晚干什么？)

- Marcadores de reformulación: explicativos 就是说 (他昨天生病了, 就是说他今天不来上班了), rectificativos更解切地说 (他明天不来上班了, 更觔切地说他辞职了), de distanciamiento无论如何 (无论如何我想去看他 y recapitulativos 总之(总之 你没做好这项工作).

- Puntuación y párrafos. Uso de 。、「...」— 
- Formato de acuerdo con el tipo de texto. Marcas gráficas de clasificación, énfasis, referencias.

- Entonación y pausas.

\section{3-Conversación}

- Marcadores conversacionales 1 (dirigirse a alguien, saludar, empezar a hablar, cooperar, reaccionar, reforzar, asentir, implicar al interlocutor, disentir, atenuar la disensión, demostrar implicación, tomar la palabra, iniciar una explicación, pedir ayuda, agradecer, repetir y transmitir, anunciar el final, despedirse):

请问, 劳驾, 麻烦你, 对不起, 不好意思, 一言为定, 慢走, 一般而论.

\section{( 会话语气词组)}

(2)Marcadores conversacionales 2: 当然 (这件事我当然帮你忙了!), 看来 (看来我们无得早点儿去), 好巴 同意(好巴 我们走!), 加油(加油 快考完试了), 你懂马?(这件事要如此 如此的做 你懂马?).

- Recursos para las reacciones esperadas en las situaciones e intercambios usuales ("pares adyacentes"): preguntar - responder, ofrecer - aceptar / rehusar y explicar, pedir - conceder, hacer un cumplido - quitar importancia, pedir - dar (你汉语说得很好 $\rightarrow$ 哪里哪里, 还差得远呢)

- Marcadores operativos: de refuerzo (说真的: 说真的, 你想去抿?), de concreción (特别, 尤其 他们都很喜欢音乐、尤其是王小明) y de focalización (至于. 至于这件事我们明再说.

\section{4- Topicalización y focalización}

- Reconocimiento del orden normal o no marcado de los elementos en la oración: tema-rema (información conocida - información nueva): 那件事我管不了, 从这儿去远不远?. No confundirlo con la relación sujeto / predicado: el sujeto y el tema pueden coincidir (他喜欢吃水果), pero no necesariamente (那只狗我已经看过了).

- Procedimientos gramaticales frecuentes:

. Con partículas de tema o tópico (那只够啊 (嘛 / 呢) 我已经看过了).

. Con la construcción 是...的 (我们是九点钟关门的).

(2) Poniendo al agente como protagonista cuando el tópico es el CD: 是... 的 y no la pasiva occidental (那副画是王太太画的 y no 那副画被王太太画了). Especial énfasis en evitar este calco sintáctico.

- Elipsis de la información compartida.

- Realce de la información compartida y de la información nueva con recursos léxicos, de entonación y acentuación: 大象我已经看过了 frente a 我已经看过了大象.

- Focalización e intensificación de un elemento (exclamación, enumeraciones, repeticiones, léxico con rasgo +intenso (了不起), grado superlativo (好极了,非常好, 累死了), acentuación, alargamiento fónico, silabeo.

\section{5- Cortesía}

- Formas de tratamiento de uso frecuente: personas gramaticales (您), nombres de 
tratamiento social (先生，教授，大使，“大夫) uso de fórmulas (请教，麻烦您，留步，效劳，㤐慢）y expresiones hechas (哪里哪里，不敢当 过奖.

- Formas y expresiones para las funciones sociales (dar órdenes, pedir, corregir...: 麻烦您, 请(尔, 秒等, 没想到).

- Respuestas cooperativas: repetición de partículas, expresiones apropiadas... (好的) 没吅题 当然 谁总不是呢.

\section{6- Inferencias}

- Sentido implícito en las expresiones y situaciones habituales (你吃饱了吗?, 你去哪儿?, 时间人晚了 $\rightarrow$ 你快一点儿/ 我要䀧觉..), en las respuestas demasiado breves, o demasiado prolijas y en el tono irónico.

\section{LÉXICO Y SEMÁNTICA}

\section{1- Vocabulario}

- Expresiones frecuentes en diferentes situaciones formales e informales para las funciones que se trabajan (Ver I, 1 y 3): 几岁 / 多大了/多大年纪了?, 你属什么?, 多少钱?...

- Vocabulario de las situaciones y temas trabajados; variantes (formal - informal:) estándar (Ver II, 1). 你好抿? / 你怎么了?, 你姓什么? / 您贵姓?，你干麻 / 你做什么?, 你好? / 久仰大名...

(2) Sintagmas lexicalizados y secuencias estereotipadas, (“colocaciones") de uso frecuente: 晚安, 干杯, 恭喜恭喜, 忙中有错, 忙不过来一模一样, 一言为定, 自言自语 不知如何是好...

Otros sintagmas lexicalizados:

乱七八糟 流口水 出洋相 糊里糊余水土不服 满载而篮天白云。一心意..

(2)Expresiones idiomáticas muy habituales:

生日快乐 新年快乐 万事如意、恭喜恭喜，恭喜发财...

Otras expresiones idiomáticas: 身体建康, 礼多人不怪 不到长城非奴又 人死不能复生, 成家立业, 入境遀谷...

\section{2- Formación de palabras}

- Formación de palabras por derivación:

. Valores de los prefijos 在-, 第, 初, 老, 小, 好, 难, 可-.

. Valores de los sufijos -的 -们 -儿,-学, -家 -化 -子, -头, - 店, -员

. Valores de los interfijos 得y不

(2)Formación de palabras por composición de dos lexemas (小说 河马 分散 眼厂, 吃醋 开刀, 溜水, 大小, 热心 左右, 风行, 自动).

Formación de palabras por composición de tres o más lexemas (公共汽车, 出租气车, 电了邮件, 羊角面包).

- Formación de palabras por parasíntesis (小说家, 工楸化, 语文学).

Nominalización: a través de sufijos (现代化) o por recategorización (找不到工作). 
- Formación de palabras por acortamiento (acronimia: 北京大学 $\rightarrow$ 北大 公共汽车 $\rightarrow$ 公车, 北京外语大学 $\rightarrow$ 北外)

- Transliteración de siglas de uso frecuente (provenientes del inglés especialmente: ROC: 中华民国 RPC: 中华人民共和国, AIDS o SIDA $\rightarrow$ 艾滋病 TOEFL $\rightarrow$ 托福 考试, $\mathrm{ONU} \rightarrow \quad$ 联合国, $\mathrm{ONG} \rightarrow$ 非政府组织, NATO u $\quad$ OTAN $\rightarrow$ 北大西洋公纵组织, DVD, VCD $\rightarrow$ 影碟机)

- Transliteración de palabras extranjeras de uso frecuente (McDonalds $\rightarrow$ 麦当劳, Kentucky $\rightarrow$ 肯德基 pizza $\rightarrow$ 比涝饼, motorcycle $\rightarrow$ 摩毛汽车)

\section{3- Significado}

- Palabras sinónimas o de significado próximo 1:

再/又/也/还大家/认 比/比较以为/认为，完/完了/做玩/完做 一点儿/ 有一点儿/多一点儿, 吗/ 呢/吧/了, 常常/ 非常/ 往往/很长/ 往常, 或/ 还/ 或是/ 还是 给/对/跟/和/向/为/往 能/会/可以/行/可能/也许, 先/首先 了解/认识 / 懂/明白

Palabras sinónimas o de significado próximo 2: 感到/ 觉㝵 想/ 心想 要/ 愿意, 刚/ 刚才, 渐斩訨/ 慢曼地 来不及/ 没村间, 总是/ 永远/一直, 正/正在/正好, 往往/

常常, 场合/ 情兄, 只/ 只是/只要/只有, 得了/得到/ 取得, 甚至/连 礼貌/ 规矩

- Campos asociativos de los temas trabajados 1: 国家(中国 台湾 意大利荷兰 爱尔兰, 比利时, 瑞士瑞典 韩国, 香港 西藏, 尼泊尔, 新加坡, 印度,

印尼，俄罗斯，墨西哥，智利，哥伦比亚，阿拉伯 阿富汗，土耳其 摩各哥, 埃及 以色列，巴勒斯坦..), 服装

(大衣毛衣 外衣西服雨衣裤子, 裙子, 披肩, 睡衣泳衣 補衫, 内裤, 腰带, 乳罩 袜 子...), 水果

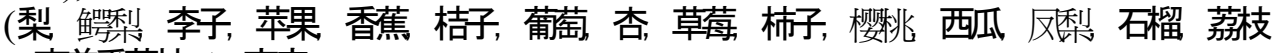
南美番荔枝..), 商店

（饭店 银行, 由局，咖非官，书店网吧电景琓 药房，洗衣店，花店，水果店，烟店，眼镜 店，超市，图书倌..)，身体

（头 脸 眼晴、嘴巴 鼻子, 耳朵 牙齿, 喉龙 脖子, 肩膀 北部 关节, 肌肉, 收 手臂,

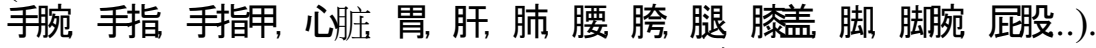

(2) Campos asociativos de los temas trabajados 2: 运动

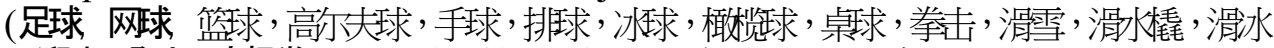
溜水 登山 太极拳 马术, 自由摔交, 汽车赛, 摩托越妇了赛...), 运输工具

(汽车, 火车, 船, 计程车, 游览车, 公共气车, 地铁, 电车, 三轮车, 自行车, 摩轮车, 卡车, 捷云...), 个性 性格(文静

活发, 内向外向, 懂事, 合理, 乐观, 悲观, 害羞, 严肃, 严格, 保守, 霸道, 迷糊, 紧张, 笨

笨蛋 笨手笨脚, 顽固, 固执, 暴躁, 暴力, 残忍, 复杂, 孤辟, 骄敖, 谦虚, 虚为, 小气, 大方, 鼻鄙..), etc.

- Proformas (palabras de significado abierto: 说 做 干, 事情..) y sustitución por las correspondientes precisas en el contexto.

- Hiperónimos de vocabulario frecuente (桔子 $\longrightarrow$ 水果，松树 $\longrightarrow$ 树，玫瑰花 $\longrightarrow$ 花 $\longrightarrow$ 植扬).

- Palabras antónimas usuales ( 内向/外向 牙观/悲观 文静/活发, 骄敖/ 谦虚 开放/ 保守,合理/ 顽古) 
- Polisemia y doble sentido en palabras de uso frecuente (客气 哪里, 脸 五脸.

- Palabras próximas formalmente, que suelen producir dificultad (书/ 树/鼠/数 十四/四十, 松树/松鼠.

- Definición de palabras. Términos de parentesco 1: 丈夫 父亲 $\rightarrow$ 爸爸 祖父 $\longrightarrow$ 爷爷 $\longrightarrow$ 爸甾的的父亲

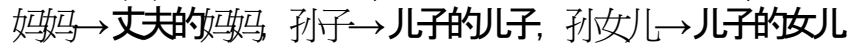

- Definición de palabras. Términos de parentesco 2:

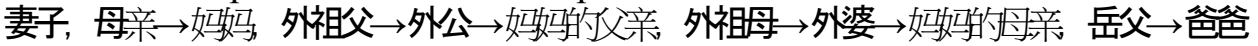
$\rightarrow$ 妻子的爸爸 岳母 $\rightarrow$ 妈马 妻子的妈马，外孙 $\mapsto$ 女的儿子, 外孙女 $\rightarrow$ 女的女儿

- Uso del diccionario. Búsqueda por el sistema de pinyin y por el sistema de radicales.

- Falsos amigos e interferencias léxicas frecuentes (con la LM u otras segundas lenguas: 绿色笑话en vez de黄色笑话.

\section{FONOLOGIAA Y ORTOGRAFİA}

- Consolidación y refuerzo del reconocimiento y producción de los fonemas vocálicos y consonánticos.

- Insistencia en los fonemas que presentan mayor dificultad: $b / p, d / t, g / k, n / n g$, $\mathrm{j} / \mathrm{q} / \mathrm{x}, \mathrm{zh} / \mathrm{ch} / \mathrm{sh}, \mathrm{z} / \mathrm{c} / \mathrm{s}$.

- Insistencia en la transcripción de los fonemas anteriores.

- Reconocimiento de las variantes más sobresalientes de realización de los fonemas.

(2) Reconocimiento de la relajación articulatoria en lenguaje familiar y coloquial.

- Diptongos y triptongos.

- Estructura de la sílaba y separación silábica: “(cons.) vocal (nasal: alveolar y velar)".

(2) Ventajas e inconvenientes de un sistema fonológico y silábico de tanta simplicidad.

- Acento enfático.

- Entonación: refuerzo de los patrones característicos y estudio de otros especiales. Combinación de los distintos grupos fónicos que componen la oración.

- Entonaciones especiales en las oraciones interrogativas, exclamativas y adjetivas o de relativo.

- Entonaciones especiales en las oraciones con algún elemento topicalizado, focalizado o enfatizado.

(2) Entonación para las funciones comunicativas trabajadas.

- Insistencia en los tonos.- reconocimiento y producción. Cambios tonales en 一, 七八不, 得, 背, 量 Tono shandi y variaciones morfofonológicas (un mismo carácter cambia de tono según desempeñe una u otra categoría gramatical: 背, 量 $\rightarrow \mathrm{N}$ y V)

- Insistencia en las palabras con la misma sílaba pero diferente tono (马/ 骂/ 玛/妈 / 码/吗/ 嘛买/卖/埋 毛/猫/帽/貌, 慢/满/ 馒/ 漫 
- Insistencia en los caracteres homófonos pero no homógrafos (misma pronunciación y mismo tono pero distinta escritura: $\mathrm{ba} \rightarrow$ 八 八吧 扒 疤 芭笆 mò $\rightarrow$ 末 抹 沫 莫 墨 磨.

- Ritmo. Insistencia en la tendencia al ritmo binario y a las palabras bisílabas del chino mandarín (葡萄, 学校 漂亮). Repercusiones en la sintaxis, en el léxico y en el lenguaje literario.

- Consolidación y ampliación de abreviaturas (北京大学 $\rightarrow$ 北大 公共汽车 $\longrightarrow$ 公车, 北京外语大学 $\rightarrow$ 北外).

- Consolidación y ampliación de siglas provenientes de otros idiomas (sobre todo del inglés: HSK $\rightarrow$ 汉语水平考试 AIDS o SIDA $\rightarrow$ 艾滋病 TOEFL $\rightarrow$ 托福-考试, $\mathrm{ONU} \rightarrow$ 联合国, $\mathrm{ONG} \rightarrow$ 非政府组织 $\mathrm{NATO}$ u OTAN $\rightarrow$ 北大西洋公组组织

- Consolidación y refuerzo del orden de los trazos. Alteraciones según la posición.

- Ortografía cuidada del vocabulario de uso: número de trazos, orden y proporción de las partes.

(2) Reconocimiento y uso de 1.800 caracteres.

- Puntuación: usos del punto y aparte, punto y seguido, dos puntos, punto y coma, coma, coma enumerativa, comillas y subrayado.

\section{OBJETIVOS LINGÜÍSTICOS del Nivel Avanzado 2 (B2 del Marco). CHINO}

Uso contextualizado de los recursos programados en cursos anteriores y de los que se listan a continuación, para llevar a cabo las actividades y funciones comunicativas del nivel. Se recogen y amplían los contenidos del nivel avanzado 1 y se destacan con un (2) los apartados con aspectos nuevos. Frente al nivel B1, aquí incluimos también el estudio de los matices propios de los diversos registros: culto, coloquial, técnico, literario, periodístico, publicitario, administrativo...).

\section{GRAMÁTICA}

\section{1- Oración simple}

(2) Actitud del hablante y modalidades de oración: modalidad enunciativa (我坐地铁回家了), interrogativa（这种情况我们要延续到什么时候?, imperativa (别动!), exclamativa (再加上我必须做的事!), desiderativa（要是没下雨, 该多好!; 谁能像你这样! ) y dubitativa (+ afirmativas, negativas y enfáticas); casos especiales en las alteraciones del orden y elipsis de elementos. Entonación de los casos anteriores.

(2) Orden de los elementos en cada tipo de oración句子结构: posición del sujeto (你要我做什么?) y de los complementos (我这个星期六要和他彻底的研究此问题/星期六，我要彻底的和他研究此问 题). Implicaciones de significado de la diferente organización informativa del texto (ver Discurso: tematización y focalización).

Elipsis de elementos (我要喝咖啡, 他也要). 
- Refuerzo de las oraciones impersonales (有 / 是, 刮风了, 安静, 活到老学到老). Usos especiales de有 $\mathrm{y}$ 是.

- Oraciones activas con 把 Formación, requisitos y usos. Suj $+(N e g)+$ Aux + 把ă C.Dir (给) $+\mathrm{V}$...: 我不要虫文些拄不关给你

Oraciones pasivas con被, 叫, 给 y让. Formación, requisitos y usos: SN1 + (Neg) bèi被 SN2 (gěi给) V-... (永原常常被他老伊鸟.

- Oraciones con la construcción 是...的. Requisitos, funciones y usos (你是怎么来的? $\rightarrow$ 我是坐飞机来的). Repercusiones de la alteración del orden: Suj $(+\mathrm{Neg})+$ 是... $+\mathrm{V}$ 的; $\mathrm{Suj}$ 是 $+\mathrm{V}-\mathrm{CD}+$ 的; Suj 是 $+\mathrm{V}$ 的 $+\mathrm{CD}$ (我们不是九点钟开门的 我们不是九点钟开的门).

(2) Usos de la pasiva del chino frente a los de la pasiva en español o en inglés. Diferencias con la construcción是...的. Casos problemáticos: enfatización del agente cuando el tópico es el CD (*那副画被愁太为画了/ 那湢画是黎太太画的

(2) Interjecciones usuales para reaccionar en diferentes situaciones (哇，噢，哦)

\section{2- Oración compleja}

- Coordinación afirmativa y negativa. Refuerzo y usos especiales de la coordinación copulativa又...又，也...也，一方面...方面，并且 / 而且， 不但...也, disyuntiva 还是 或是y adversativa 但是, 不过, 然而, 倒是

- Subordinación adjetiva (o de relativo): especificativa (P.Rel.+ 的+N. [Prop. Adjetiva Especificativa的] $+\mathrm{N}$ ) frente a explicativa (N, [Prop. Adjetiva Explicativa] 的], $+\mathrm{N})$.

(2) Cambio en el orden de los deteminantes (posesivos, demostrativos, indefinidos y numerales) respecto a la proposición de relativo y al nombre núcleo (这三个戴眼镜的学生都很用功/戴眼镜的这三个学生都很用功).

- Utilización de 所delante del verbo en las proposiciones adjetivas sin consecuente expreso y en función de atributo (你的帮助是我所需要的). Eliminación del nombre núcleo en la subordinación adjetiva de carácter genérico (大卫是最需要我们帮助的 (人))

- Oraciones de "Verbos en serie" -para expresar la subordinación nominal o completiva

（你装电话很方便，我父母要我学英文，他命令你扫地， del español我买一串项链很值钱, 他写信抽烟.

(2) Repetición y transmisión de información, peticiones, órdenes, consejos, etc. (她劝我参加会议; 你闭嘴; 他说他到的时候打电话给我). Transformaciones implicadas en la repetición de las propias palabras o de las palabras de otros según la situación de comunicación（这个星期来看我 $\rightarrow$ 他叫我上个星期去看他）. Trabajo detallado con los casos en que un SN es simultáneamente el CD del primer verbo y el sujeto del sujeto (construcciones pivotales: 他命令你扫地). (Ver Discurso: apartados de Cohesión e Inferencias).

(2) Subordinación adverbial (o circunstancial). Consolidación y refuerzo de los nexos: temporal 1: - 的时候, 一以前 $\mathrm{y}$-以后; temporal 2: 一边...一边, 一 ... 就 y V-了... 就; condicional 1: 要是, 如果, 假如, 假使... 就 (也); condicional 2: 只要...就, 除非, 要不是...就, 不是...就是...要不然就是, 只有...才; causal- 
consecutiva : 因为 / 由于... 所以 / 就, 因为...的关系... 所以 / 就; concesiva : 虽然... 倒 / 可是 / 还是, 就是 ... 还, 无论 ... 都 / 也; final: 为的是, 省得, 是为了...才...的

\section{3- GRUPO DEL NOMBRE}

- Funciones del grupo del nombre: 的 $1 /-$ 的 $2 /-$ 的 $3 / \varnothing$.

\subsection{1- Nombre}

(2) Refuerzo y ampliación de las clases de nombres.

- Formas léxicas de indicar el concepto de género (男伖/ 女朋友)

- Formas de indicar el concepto de plural: -们, 都, 几, 些 (老们门 学生们.

- Vocativo expresado entre pausas (对了, 路易斯, 别忘了打电话给我)

\subsection{2- Determinantes}

- Posesivos. Refuerzo y ampliación de los usos de 我的, 你的, 他的 (你们抽照. Condiciones para la eliminación de la partícula 的 (我爸爸).

- Demostrativos. Usos especiales de 这 y 那 (这个学生 那些小孩子. Connotación despectiva del demostrativo.

(2) Indefinidos 1. Usos especiales de 几, 些 $\mathrm{y}$ 每. Indefinidos 2. Usos especiales de整 y某一.

- Numerales. Formas y usos especiales. Insistencia en 二, 两(我写了两封言了), 俩 (我们俩), 零 (七刀零五百零五 y en los cardinales con el prefijo 第 (第一次). Gestos de los números y sistema monetario: Det. Num.+ Clas. 块 / 毛/分 + 钱. Años, matrículas y teléfonos

- Interrogativos. Refuerzo de 什么, 几 y 多少.

(2) Uso interrogativo e indefinido (疑司助词及不定词) de 谁, 什么, 怎么, 怎么样, 为什么 多少/ 几 jì + Clas., 哪儿哪里, 哪+Clas., 干公y 什么时候

- Combinatoria y posición de los determinantes respecto a los clasificadores (o palabras medidoras) y al nombre núcleo (你(的)那两位外国朋友).

- Marca cero: anteposición verbal (determinación贼跑了) frente a posposición (indeterminación跑了贼). Equivalencia en español: artículo determinado / indeterminado (el ladrón / un ladrón). Otros valores y casos especiales.

\subsection{3- Clasificadores o palabras medidoras}

- Consolidación y refuerzo de usos de los clasificadores individuales: 把本条只 张枚 所位匹件, 口, 个.

(2) Valores estilísticos y figurados de su uso deliberadamente "inapropiado": registro literario, periodístico y publicitario.

- Consolidación y refuerzo de usos de los clasificadores colectivos: 对, 双 打, 十, 千, 行, 套副帮连流

(2) Valores estilísticos y figurados de su uso deliberadamente "inapropiado": registro literario, periodístico y publicitario.

- Consolidación y refuerzo de usos de los clasificadores partitivos: 份部块团, 半, 把栏片, 段点终轴 
(2) Valores estilísticos y figurados de su uso deliberadamente "inapropiado": registro literario, periodístico y publicitario.

- Consolidación y refuerzo de usos de los clasificadores transitorios:包, 袋, 瓶罐 碗 杯, 篮抽屈盒箱书架

(2) Valores estilísticos y figurados de su uso deliberadamente "inapropiado": registro literario, periodístico y publicitario.

- Consolidación y refuerzo de usos de los clasificadores estándar: 公分, 公寸, 公里, 斤, 克, 本点刻分, 秒, 毛天年.

(2) Valores estilísticos y figurados de su uso deliberadamente "inapropiado": registro literario, periodístico y publicitario.

- Combinatoria de un mismo nombre con distintos clasificadores: Det. + Clas. + N (一张支票/一本支票, 一根筷子/一双筷子/一把筷子).

\subsection{4- Complementos del nombre}

- Adjetivos (invariables). Consolidación y refuerzo.

- Combinatoria con 的: ausencia (好人, 红花, 国立大学) / presencia (很好的人). Adjetivos combinados con ciertos sustantivos de carácter literario y que tienen su origen en chino clásico: ausencia de的.

- Posición y combinacióndel adjetivo con otros elementos de un SN: Posesivo + Demostrativo + Numeral + Clasificador + Adjetivo + Nombre ( 我这两个亲爱的朋抆).

- Posición (antepuestos al nombre y especificativos). Diferencias con los verbos estativos de cualidad (好人 / 人好)

(2) Refuerzo y ampliación de los grados del adjetivo 1. Utilización de 很-, 太-, 更-, 比较-, 最- . Casos especiales.

(2) Refuerzo y ampliación de los grados del adjetivo 2. Utilización de -极了, 死了, 挺-。的, -的不得了. Casos especiales.

Adjetivos que no admiten el grado

- Casos de lexicalización de “Adj + N" (黄豆香烟.

- Valores de los adjetivos reduplicados + partícula 的-de (干干净净的).

- Adjetivos y verbos de cualidad: características comunes y diferenciadoras (漂宫 短 矮 瘦难过.

(2) Interferencias con ser / estar + Adj. del español. Calcos y errores frecuentes.

- Otras formas de complementos del nombre (delante del nombre-núcleo): nombre en aposición (黄河, 黎部长), adjetivo en aposición（约翰, 累了, 回家了）y oración adjetiva o de relativo (我们想买的那个房子在乡下).

\subsection{5- Pronombres}

(2) Refuerzo y ampliación de las formas, funciones, posición, combinatoria, uso / omisión.

- Pronombres personales: funciones, formas, combinatoria y colocación.

- Formas de tratamiento habituales (你/佨).

- Importancia de la ausencia de pronombre personal (我ø买了ø, frente al español se la compré). 
(2) Obligatoriedad del pronombre personal con el marcador activo把 y el pasivo被.

- Pronombres posesivos, demostrativos, indefinidos y numerales.

- Pronombres interrogativos: 谁, 什么 $+\varnothing$, 哪 + 个 $+\varnothing$, 几 + 个 $+\varnothing$, 多少 $+\varnothing$.

(2) Refuerzo y ampliación de la relación entre los pronombres interrogativos e indefinidos: 谁, 什么, 怎么, 怎么样, 为什么多少/ 几jī + Clas., 哪儿。哪里, 哪+Clas., 干么 $\mathrm{y}$ 什么时候

- Pronombre relativo 的.

- Pronombre reflexivo 自己。

(2)Formas de expresar en chino los matices del se impersonal, se pasivo reflejo y el se medio del español. Calcos y errores frecuentes.

\section{4- GRUPO DEL VERBO}

- Núcleo-verbo-y complementos.

- Falta de concordancia del verbo con el sujeto. Mecanismos para detectar el sujeto y los distintos tipos de complementos.

\subsection{1- Verbo}

- Propiedades del verbo. Refuerzo de las clases de verbos.

- Maneras de expresar el concepto de tiempo: presente, pasado, futuro y habitualidad. Usos especiales.

(2)Refuerzo y ampliación de los valores aspectuales: perfectivo - $了$, imperfectivo progresivo在-, 正在, 正在-...呢, imperfectivo durativo -着,perfecto experiencial 过 1 , perfecto reciente -过 2 , incoativo -起来, continuativo -下去. Otros usos derivados o que se apartan del valor esencial.

(2) Clases y usos de los verbos resultativos gramaticales 到, 见, 起了, 好 (这只手表人贵, 我买不䞟 y léxicos (推开, 穿破撕卒打坏, 撞开). Su combinación con los potenciales 得y不 (推得开/ 学不了).

- Verbos direccionales simples去, 来 上下, 走, 到, 在 (拿出来). Su combinación con los potenciales 得 $\mathrm{y}$ 不 (拿得来/搬不去).

- 的 $1 /$-的 $2 /-$ 的 $3 / \varnothing$.

(2) Verbos direccionales compuestos (搬进出. Su combinación con los potenciales 得y不 (拿得下来/ 不上去).

- Valores de los verbos reduplicados (看看, 检查检查). Usos especiales.

- Valores modales a través de verbos auxiliares: 会, 能, 可以; 要, 得, 应该, 必须.

- Formas de expresar el imperativo: 不要y 别. Suavización a través de partículas modales (吧).

- Perífrasis verbales de uso frecuente (喜欢游泳，想去).

- Verbos transitivos.- matices de las 4 posiciones del CD: a- (Suj) + V+CD

(学生已经故完功果. b- (Suj) + CD + V (学生功颗经做完J). c- (Suj) + 把CD + V

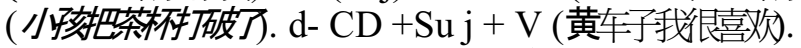

- Verbos que exigen CD y CI: 给, 送, 还, 付.

(2) Refuerzo y ampliación de los diferentes usos de 是y de 有. 
(2) Los verbos auxiliares, los verbos de estado y los verbos adjetivales (o de cualidad). Su comportamiento con la negación y con los sufijos aspectuales.

- Los clasificadores verbales 次, 边, 回y 趟.

- Voz activa con 把 Formación, requisitos y usos. SUJ + (NEG)+ AUX + 把C.DIR ( 给) $+\mathrm{V}$...: 我不要圤这些拄不送给你 Combinación con la negación y con los verbos auxiliares.

- Voz pasiva con被, 叫, 给 y 让. Formación, requisitos y usos: SN1 + (NEG) 被 SN2 (给) V-... (永原常常被他老伊号乃. Combinación con la negación y con los verbos auxiliares.

(2) Usos de la pasiva del chino frente a los de la pasiva en español o en inglés. Diferencias con la construcción是...的. Casos problemáticos: enfatización del agente cuando el tópico es el CD (*那副画被黎太太画了/ 那副/画是黎太太画的

\section{5- ADVERBIO y locuciones adverbiales}

- Refuerzo de los adverbios y locuciones adverbiales de tiempo (早晚以后以前 现在再, 再一次已经还昨天前天 马上那时那么 永远 有时候 常常 有一次 今天 明后为。

- Refuerzo de los adverbios y locuciones adverbiales de lugar (这里这么那里, 那么

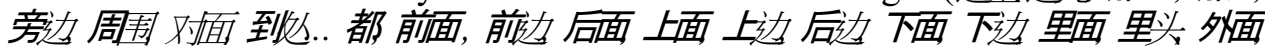
外边.

(2) Refuerzo y ampliación de los adverbios y locuciones adverbiales de modo

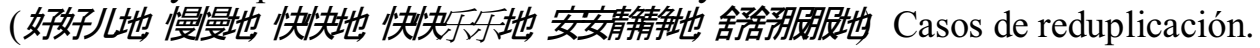

- Posición respecto al verbo y al sujeto: adverbios de tiempo y actitud / adverbios de modo. Posición preverbal / posverbal de los adverbios de tiempo: puntualidad / duración (我三点钟吃饭 / 我吃了三个小时的反). Adverbios móviles (将来, 昨天) frente a adverbios fijos (只, 就, 才/就).

(2) Refuerzo y ampliación de los adverbios de cantidad o de medida ( 几乎, 很 很多, 恨少, 太绝不.. ) modificando a diferentes categorías 很累, 很多朋友, 开得很快- y a otro adverbio - 很远- ). Usos de 一点儿 y 有一点儿. Gradación del adverbio. Otros usos derivados o que se apartan del valor esencial.

- Adverbios interrogativos: 哪儿，什么时候，怎么，怎么样，什么时候，为什么。 Posición en la oración. Calcos y errores frecuentes.

- Refuerzo de los adverbios de afirmación, negación y duda: 是对真不, 没, 从不, 从未 也不, 也没, 完全不, 也许, 或许

(2) Adverbios negativos y su interación con otros adverbios.

El adverbio 刚 y el sustantivo de tiempo 刚才。

\section{6- PARTÍCULAS}

- Refuerzo de las clases de partículas y de su posición en la frase.

- Usos de la partícula 的: posesión (我的电脑), relativo (我租的房子), pronominalización (红色的), construcción 是...的 (他是坐飞机来的), etc. 
(2) Partícula de grado 得. $\mathrm{Su}$ negación (买得起 / 买不起). Requisitos morfosintácticos y semánticos.

(2) Partícula modal oracional 了 frente a sufijo verbal perfectivo了: (已经) $\mathrm{O}+$ 了 1 $\mathrm{V}+$ 了... (我买两本书了/ 我买了两本书). Casos de ambigüedad (他来了).

- Repercusiones del empleo de la partícula modal oracional 了 frente a sufijo verbal perfectivo-了en la negación: 还没 (有) $+\mathrm{V} \ldots$ 呢 / 没 $+\mathrm{V}+\varnothing \ldots$ (我还没买书呢/ 我没买书)

- Las partículas modales oracionales.- Formas y usos (cambio de situación, decisión tajante, certidumbre, énfasis, extrañeza, reafirmación, suposición, aprobación, contrariedad, suavización de órdenes, familiaridad y

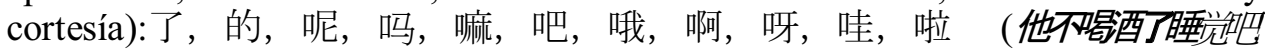

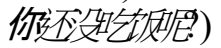

\section{7- ENLACES}

1.7.1- Conjunciones y locuciones conjuntivas

- Refuerzo de los coordinantes copulativos: 并且, 而且，不但...也/还，不但...连...也都，又...又, 一方面... 一方面, 越...越.

- Refuerzo de los coordinantes disyuntivos: 还是, 或是, 或者是.

(2) Consolidación y ampliación de los coordinantes adversativos 1 : 可是, 但是, 不过; coordinantes adversativos 2 : 然而, 倒是.

(2) Consolidación y ampliación de los subordinantes: temporales: -的时候, 以前, 以后; temporales 2: 一边... 一边, 一 ... 就 y $\mathrm{V}$-了... 就.; condicionales $\mathrm{e}$ hipotéticos 1: 如果 / 假如 / 要是 / 假使.... 就/也. y condicionales e hipotéticos 2: 只要... (就), 除非, 要不是...就, 不是...就是...要不然就是, 只有...才; 的话...就.; causales-consecutivos: 因为 / 由于/ 因为...的关系 ...所以 / 就.; concesivos 1: 虽然 ...倒 / 可是 / 还是 y concesivos 2: 即使 / 就是...也 / 还, 无论 / 不管...都 / 也; finales 1 : 为了 y finales 2 : 为的是, 省得, 是为了...才/而...的; comparativos: de igualdad ( $\mathrm{A}$ 跟 $\mathrm{B}$ 一样 $+\mathrm{V}$ ), de superioridad $(\mathrm{A}$ b ̌ 比B $+\mathrm{V})$ y de inferioridad (A 沒有-B 那么 $+V, A$ 不如B那么 $+V$ ).

\subsection{2- Preposiciones y posposiciones}

- Preposiciones (coverbos): consolidación y ampliación.

- Posición en la oración: "Sujeto y / o tópico + [CoV.-SN] + V" （上月我替张老师上课 愁青昨天到乡下去厅

(2) Usos detallados de 给, 从, 在, 跟, 坐, 用, 替, 离, 像, 叫.

(2) Usos detallados de 除了, 按, 沿, 关于.

- Posposiciones (SN+part. locativa -posposición-): consolidación y ampliación.

- Posición: SN+part. locativa (posposición) (他们把这些书西放在桌子底下

- Usos detallados de 上, 下, 里, 前面, 后面, 对面, 右边, 左边, 旁边, 附近.

(2) Presencia / ausencia de 面, 边, 头. Otros usos derivados o que se apartan del valor esencial. 


\section{DISCURSO}

\section{1- Cohesión}

- Refuerzo de los procedimientos para mantener el tema: repeticiones (intencionadas) (李先生人很好). . Recursos de sustitución sencillos con referente claro: elipsis, pronombres y adverbios o expresiones con valor anafórico (那个，那一年，那儿，一样的地方，那件事情，那个问题).

(2) Refuerzo y ampliación de los procedimientos léxicos: sinónimos, hiper / hipónimos（锤子，钳子>工具）, a través de uno de los términos que entran en la

definición（军人，队长，长官），nominalización（立刻陷入爱情....恋爱是... .) , proformas léxicas: 问题，事件，主题

(必须向主管提出加薪的问题，但主管从来不提这个主题). Expresiones referenciales: 这件（该）事，已经提过的（上个月有一个关于Garcia Marquez的小说及该作家对西班牙文学影响的会议). Elipsis del nombre núcleo de un grupo nominal, en los casos en que se sobreentiende por el contexto situacional o lingüístico（由于火车故障的原因所有的旅客都必须下车，有的（旅客）走 路离开，有的（旅客）在原地等着）. Posición preverbal para los nombres ya presentados (贼跑了 frente $a$ 跑了贼).

- Coherencia de la temporalidad verbal en el discurso (那个时候).

- Conectores

- Refuerzo de conectores 1: 又...又，也...也，一方面... 一方面，并且 /而且， 不但...也 (还), 因为, 所以，的时候，另外， 只要..就 除非, 要不是..就 不是..就是..要不然就是, 只有...

- Refuerzo de conectores 2: 因为/由于... 所以/ 就 因为的关系.. 所以 / 就, 虽然... 倒 / 可是 / 还是, 就是 ... 还, 无论 ... 都 / 也, 为的是, 省得, 是为了 ... 才 ... 的.

(2) Estudio detallado de algunos conectores aditivos: 除了......之外

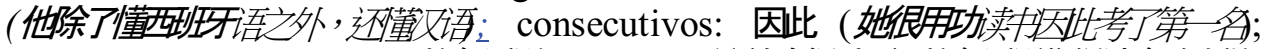
contraargumentativos: 换向话说 (这件事很重要, 换向话说你得认真地去做; justificativos: 既然 (既然你已知道了, 我就没必要告雁尔了)

\section{2- Organización}

- Marcadores de iniciación: fórmulas de saludo, presentación, introducción del tema: 请问, 劳驾, 麻烦你, 对不起, 不好意思, 首先(开会之前, 我们首先清无先生讲语

(2) Refuerzo y ampliación de los marcadores de estructuración: ordenadores (de apertura, de continuación y de cierre) comentadores, digresores: 那么，首先，顺便 (开会之前，我们店先请下先生讲话顺更可一下，你今晚开什么?)

- Marcadores de reformulación: explicativos 就是说 (他昨天生病了, 就是涚他今天下来广班了), rectificativos更确切地说

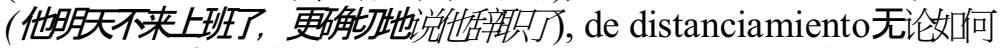
（无论如何我想去看他 y recapitulativos 总之(总之 你没做娗项工作．

(2) Refuerzo y ampliación de la relación entre puntuación y párrafos. Empleo de los signos de puntuación como marcadores del discurso (con especial atención al 
significado discursivo de los signos punto y coma, puntos suspensivos, interrogación; exclamación; paréntesis; corchetes; guión; raya). Correspondencia entre los párrafos y los temas del discurso.

- Marcas gráficas de clasificación, énfasis, referencias (convenciones de distribución y organización del texto para esquemas e índices; negritas, subrayados y comillas).

(2)Refuerzo y ampliación de la relación entre entonación y pausas. La entonación y las pausas como marcadores de unidades discursivas y de relaciones de sentido (correspondencia entre unidades melódicas y signos de puntuación; identificación y producción de los patrones melódicos propios de los actos de habla y las estructuras discursivas del nivel).

Elementos propios de la conversación (en diferentes registros y actitudes)

- Uso del pronombre personal explícito: como marcador de cambio de turno（你觉得我说得如何?-我觉得你有道理）， como indicador de subjetividad (我不同意。我, 我的看法是...) , como marcador de contraste discursivo（我在这里, 你走) y para deshacer ambigüedades（我明天打电话给你）。

(2)Refuerzo y ampliación de los marcadores para dirigirse a alguien según la situación 1: formas de tratamiento; 对不起/不好意思请.../轻看), saludar（艾+名字=你最近如何？哇+名字，好久不见，很高兴看到你）， responder a un saludo (很好, 谢谢, 你呢? 很好, 老样子), solicitar al interlocutor que empiece a hablar（你觉怎么样？老兄，我想问你一件事?）， empezar a hablar

(对了, 你知道吗? , 我想你一定不知道。就是这样, 你看...), cooperar (对啊! / 是这样, 知道...吗? ), reaccionar

(真的! 哇! 是吗? 别吓我了! 说真的!), reforzar（是这样的，当然！确定！实际上！毫无疑问！）。

- Marcadores para dirigirse a alguien según la situación 2: implicar al interlocutor (对吧! 你怎么知道...你已经知道应该...), asentir, con distintos matices（别再说了! 当然!一般来说, 我同意, 你说的我大部分都同意..., 就是说... ; 好，根据我的看法)， contradecir， con distintos matices (好, 但...,没这回事; 无论如何)， clarificar las opiniones

（并不完全这样，而是.....我说要说的是....) demostrar implicación（令我太意外了! 别说了! 太不可思议了! 台令人惊奇了! ).

(2) Refuerzo y ampliación de los marcadores para dirigirse a alguien según la situación 3: tomar la palabra（我想要说的)， iniciar una explicación ( 没什么，意思是说...没什么 ...你想想看... ; 我告诉你.... ) , repetir y transmitir (posibilidad de omisión del verbo de lengua introductor; reproducción de enunciados interrogativos; uso de expresiones citativas), interrumpir la explicación (对不起，请等一会儿，是这样的...;劳驾，但是... 我很高兴你能 告诉我，不过...）, anunciar el final（就是这么一回事，就是如此）, despedirse（好吧，没事，再说了）。

(2)Refuerzo y ampliación de los recursos para las reacciones esperadas en las situaciones e intercambios usuales ("pares adyacentes"): preguntar por una 
persona al teléfono - responder (你好, 能否请.....?

请稍等；对不起她现在无法招烀你）, preguntar por el estado general de las cosas - responder (如何? 都好吧? 怎么样? 对这件事进展得如何? 。 还好, 谢谢), ofrecer - aceptar (我想你不希望...你不想..., 当然想; 那将很好/太好了/好极了/我将很乐意/好，我们走吧）， rehusar-insistir（你太客气了，不过….-对不起，不过...我恐怕不可能+动词 +原因 ; - 确定吗? 但是, 如果/走吧! 加点油!), pedir un favor - aceptar (你能否帮我忙? 我需要你帮我这个忙, 一 没问题，当然。是我的荣幸)，pedir ayuda-conceder ayuda

（你能否邦我忙? 我需要你帮我这个忙,一没问题，当然。是我的荣幸）， hacer un cumplido - quitar importancia（你是我最好的朋友 好了, 别说了! 别太可气了!) etc.

\section{3- Deixis}

- Formas de señalamiento en las diferentes situaciones de enunciación (conversación, teléfono, chat, carta, etc.) y en el discurso diferido y relato: uso en cada caso de los pronombres, demostrativos y expresiones de tiempo y espacio (我, 你 $\leftrightarrow$ 他, 现在, 这个时候, 今天, 昨天, 明天.... $\leftrightarrow$ 那个时候，当天，前天，后天..., 这儿，这个，来，带来 $\leftrightarrow$ 那儿, 那个, 去, 带去)。

- Deixis espacial: combinación de adverbios deícticos para concretar el lugar (在那儿上头, 这儿附近, 就在这里)

(2) Refuerzo y ampliación de la transformación de deícticos y marcadores en función de las coordenadas espacio-temporales: pronombres, demostrativos y expresiones de tiempo y espacio. Diferencias según la situación de enunciación y el registro (马上来这儿! 他说立刻来/他说立刻回家/他请我快速回家)

- Rechazo intensificado (不, 不要, 别麻烦你了).

\section{4- Cortesía}

- Consolidación, ampliación y usos especiales de las formas de tratamiento: personas gramaticales (您), nombres de tratamiento social (先生，教授，大使，大夫) uso de fórmulas （请教，麻烦您，留步，效劳，忘慢 ) y expresiones hechas (哪里哪里, 不敢当, 过奖).

- Formas y expresiones para las funciones sociales (dar órdenes, pedir, corregir.... 麻烦您，请你，稍等,没想到).

- Respuestas cooperativas: repetición de partículas, expresiones apropiadas... (好的，没问题，当然谁说不是呢).

\section{5- Inferencias}

- Sentidos implícitos de expresiones usuales en diferentes situaciones de comunicación 行，我行/好，我现在就告诉他; ¿你会开车到瓦伦西亚吗? 会，当然会，我开车去过好几次了。/会，你应该上高速公路，然后....) 
(2)Refuerzo y ampliación de la ambigüedad ilocutiva (你吃饱了吗?, 你去哪儿?, 时间太晚了 $\rightarrow$ 你快一点儿 / 我要睡觉...): información, mandato, amenaza 很晚了: información de la hora, orden para terminar, cierre de una reunión, expresión de una intención de (快点/我们快做完它/我要去睡觉)

- Implícitos en las respuestas demasiado breves, o demasiado prolijas.

- Implícitos en los tonos de voz (irónico, inocente fingido, etc).

(2) Refuerzo y ampliación de implícitos en construcciones interrogativas orientadas (他们选了约翰为系主任-i他们选了约翰做什么? i你不觉得玛莉亚对我们很不客气吗?

\section{6- Tematización y focalización}

- Reconocimiento del orden normal o no marcado de los elementos en la oración: tema-rema (información conocida - información nueva): 那件事我管不了, 从这儿去远不远?. No confundirlo con la relación sujeto / predicado: el sujeto y el tema pueden coincidir (他喜欢吃水果), pero no necesariamente (那只狗我已经看过入).

(2) Focalización con operadores discursivos（连巴哥都了解，你看就是玛莉亚没来） y con estructuras sintácticas especiales（巴哥就是我告诉他的人；就是我昨天看到的）

- Elipsis de la información compartida.

(2) Refuerzo y ampliación del realce de la información compartida y de la información nueva con recursos léxicos, de entonación y acentuación: 大象我已经看过了 frente a 我已经看过了大象.

- Focalización e intensificación de un elemento (exclamación, enumeraciones, repeticiones, léxico con rasgo +intenso (了不起), grado superlativo (好极了, 非常好, 累死了), acentuación, alargamiento fónico, silabeo.

\section{LÉXICO Y SEMÁNTICA}

\section{1- Vocabulario}

- Variedad de expresiones para cumplir las funciones que se trabajan en situaciones formales e informales (Ver I, 1 y 3), tanto para lengua oral como escrita.

- Expresiones frecuentes de español coloquial relacionadas con las situaciones y temas trabajados (厚脸皮, 真烦人). Reconocimiento de tacos frecuentes.

(2) Ampliación del vocabulario de las situaciones y temas trabajados. Ejemplo:劳工界 (下岗 (失业) 固定合约/暂时 $\rightarrow$ 请求除名, 自由业, 失业 , 加薪) ; variantes (formal-informal) estándar y registros familiares o profesionales (Ver II, 1).

- Consolidación de expresiones no muy idiomáticas, tanto habituales como más específicas, en diferentes situaciones formales e informales para las funciones que se trabajan (Ver I, 1 y 3) (几岁/多大了/多大年纪了?, 你属什么?, 多少钱?) 
- Consolidación del vocabulario de las situaciones y temas trabajados (Ver II, 1); variantes formales e informales estándar y no muy idiomáticas (你好吗? / 你怎么了?, 你姓什么? / 您贵姓?，你干嘛? / 你做什么?, 你好! / 久仰大名).

(2) Consolidación y ampliación de sintagmas lexicalizados y secuencias estereotipadas ("colocaciones"), de uso tanto frecuente como más específico (晚安, 干杯，恭喜恭喜，忙中有错，忙不过来一模一样 自言自语 不知吅何是娜。

(2) Otros sintagmas

一言为定 （乱七八糟，流口水，出洋相，糊里糊涂，水土不服，满载而归，蓝天白云， 一心一意).

- Consolidación de expresiones idiomáticas frecuentes (生日快乐，新年快乐，万事如意，恭喜恭喜，恭喜发财.

身体健康，礼多人不怪，不到长城非好汉，人死不能复生，成家立业， 入境(迶俗)

(2) Otras expresiones idiomáticas frecuentes utilizadas en diferentes registros: estándar, formal, coloquial, vulgar, etc. (对牛弹琴，开天辟地，一日干里，一毛不拢，一箭双雕，金屋藏娇，别出心 裁, 别出新意, 别创一格, 发愤图强, 发愤忘食, 高不可攀, 高步阔视, 快意当前，脍采人口， 跑了和尚跑不了庙，跑了和尚跑不了寺，跑龙套，走马观花， 人百其身，人才出众，人不可貌相，人才难得，人才辈出，人不自安，一 败涂地，死标白缠，死别生离).

\section{2- Formación de palabras}

- Formación de palabras por derivación.- consolidación, ampliación y matices especiales de los prefijos (在-, 第-, 初-, 老-, 小-, 好-, 难-, 可-), sufijos (-的, -们, -儿,-学, -家, -化, -子, -头, -店, -员) e interfijos (得 y不).

- Formación de palabras por composición de dos lexemas.- consolidación, ampliación y matices especiales (小说, 河马, 分散, 眼红, 吃醋, 开刀, 溜冰, 大小, 热心, 左右, 风行, 自动.

(2) Formación de palabras por composición de tres o más lexemas - consolidación, ampliación y matices (公共汽车, 出租汽车, 电子邮件, 羊角面包).

matices especiales

- Formación de palabras por parasíntesis.- consolidación, ampliación y matices especiales (小说家, 工业化, 语文学).

- Nominalización: a través de sufijos (现代-化) o por recategorización (找不到工作).

- Formación de palabras por acortamiento (acronimia: 北京大学 $\rightarrow$ 北大, 公共汽车 $\rightarrow$ 公车, 北京外语大学 $\rightarrow$ 北外).

- Transliteración de siglas, tanto de uso frecuente como más específico, provenientes del inglés especialmente (ROC: 中华民国, $R P C$ : 中华人民共和国, AIDS o SIDA $\rightarrow$ 艾滋病, TOEFL $\rightarrow$ 托福 - 考试-, $O N U \rightarrow$ 联合国, $O N G \rightarrow$ 非政府组织, NATO 北大西洋公约组织, $D V D, V C D \rightarrow$ 影碟机). 
(2) Transliteración de palabras extranjeras, tanto de uso frecuente como más específico (Coca Cola $\rightarrow$ 可口可乐, McDonalds $\rightarrow$ 麦当劳, Kentucky $\rightarrow$ 肯德基, $p i z z a \rightarrow$ 比萨饼, motorcycle $\rightarrow$ 摩托-汽车)

\section{3- Significado}

- Campos asociativos de los temas trabajados 1: 国家 (中国, 台湾, 意大利, 荷兰，爱尔兰，比利时，瑞士,瑞典，韩国，香港，西藏，尼泊尔， 新加坡,

印尼，俄罗斯，墨西哥，智利，哥伦比亚，阿拉伯，阿富汗，土耳其， 摩洛哥, 埃及，以色列，巴勒斯坦... 等, 服装 (大衣毛衣，外衣，西服，雨衣，裤子，裙子，披肩，睡衣，泳衣，衬衫，

内裤，腰带，乳罩，袜子...), 水果 (梨，鳄梨，李子，苹果，香蕉，桔子，葡萄，杏，草英，柿子，樱桃，西 瓜, 凤梨, 石榴, 荔枝, 南美番荕枝...),

(饭店, 银行, 邮局, 咖啡馆, 书店, 网吧, 电影院, 药房, 洗衣店, 花店 ，水果店，烟店，眼镜店，超市，图书馆...)，体 （头，脸，眼睛，嘴巴，鼻子，耳朵，牙齿，喉咙，脖子，肩膀，北部，关 节，肌肉，收，手臂，手腕，手指，手指甲，心脏，胃，肝，肺，腰，胯 ，腿，腅盖，脚，脚腕，屁股...),etc.

(2) Campos asociativos de los temas trabajados 2: 运动 (足球，网球，篮球，高尔夫球，手球，排球，冰球，橄榄球，桌球，拳击 ，滑雪，滑水棰，滑冰，溜冰，登山，太极拳，马术，自由摔跤，汽车赛 摩托越野赛...), 运输工具 (汽车, 火车, 船, 计程车, 游览车, 公共汽车, 地铁, 电车, 三轮车, 自 行车，摩托车，卡车，捷运 …), 个性，性格 (文静, 活泼，内向， 外向，懂事，合理，乐观，悲观，害羞，严肃，严格，保守，霸道，迷糊 ，紧张，笨，笨蛋，笨手笨脚，顽固，固执，暴躁，暴力，残忍，复杂， 孤僻，骄傲，谦虚，虚伪，小气，大办，早骫...), etc.

- Proformas (palabras de significado abierto: 说, 做, 干，事情...) y sustitución por las correspondientes precisas en el contexto （有，拥有，包括，有.... ; 说，指出，谈论，显出，表示，陈诉）

- Palabras sinónimas o de significado próximo 1 (再 / 又 / 也 / 还, 大家 / 人人, 比/比较，以为/认为，完/完了/做玩/完做，一点儿/有一点儿/ 多一点儿, 吗/呢/吧/了, 常常/非常/往往/很长/往常, 或/还/或是/ 还是, 给 / 对 / 跟 / 和 / 向 / 为 / 往, 能 / 会 / 可以 / 行 / 可能 / 也许, 先 / 首先，了解/认识/懂/明白).

(2) Palabras sinónimas o de significado próximo 2 (感到/ 觉得, 想 / 心想, 要 / 愿意, 刚 / 刚才, 渐渐地 / 慢慢地, 来不及 / 没时间, 总是 / 永远 / 一直，，正/正在/正好，往往/常常，场合/情况，只/只是/只要/只有， 得了/得到/ 取得, 甚至/ 连, 礼貌/ 规矩).

(2) Consolidación y ampliación de los hiperónimos e hipónimos (毛 $\rightarrow$ 发, 住家 $\rightarrow$ 靠着墙, 桔子 $\rightarrow$ 水果, 松树 $\rightarrow$ 树, 玫瑰花 $\rightarrow$ 花 $\rightarrow$ 植物).

- Palabras antónimas usuales ( 内向 / 外向, 乐观 / 悲观, 文静 / 活泼, 骄傲 / 谦虚，开放/保守, 合理/顽固) 
- Polisemia y doble sentido. Desambiguación por el contexto(客气, 哪里, 脸 $\rightarrow$ 洗脸/ 丢脸).

- Palabras próximas formalmente, que suelen producir dificultad (书/ 树/ 鼠/数, 十四/四十, 松树/松鼠).

(2) Consolidación y ampliación del reconocimiento de los rasgos léxicos y definición de palabras (丈夫, 父亲 $\rightarrow$ 爸爸,

祖父 $\rightarrow$ 爷爷 $\rightarrow$ 爸爸的的父亲，祖母，奶奶 $\rightarrow$ 爸爸的母亲，公公 $\rightarrow$ 爸爸 $\rightarrow$ 丈 的爸爸，婆婆 $\rightarrow$ 妈妈 $\rightarrow$ 丈的妈妈，孙子 $\rightarrow 儿$ 子的儿子，孙女儿 $\rightarrow 儿 子$ 的女 儿↔

妻子，母亲 $\rightarrow$ 妈妈，外祖父 $\rightarrow$ 外公 $\rightarrow$ 妈妈的父亲，外祖母 $\rightarrow$ 外婆 $\rightarrow$ 妈妈的母 亲, 岳父 $\rightarrow$ 爸爸 $\rightarrow$ 妻子的爸爸, 岳母 $\rightarrow$ 妈妈 $\rightarrow$ 妻子的妈妈, 外孙 $\rightarrow$ 女儿的儿 子，外孙女一女儿的女儿).

(2) Ampliación del reconocimiento y distinción de léxico de registro formal e informal / coloquial (去; 出席, 说-表示, 钱-钱 (口语)

(2) Ampliación del reconocimiento de los recursos del lenguaje: metáforas y construcciones de sentido figurado frecuentes en la lengua (河口)

- Profundización en los falsos amigos y en los casos de interferencias léxicas (con la LM u otras segundas lenguas: 绿色笑话en vez de黄色笑话).

\section{FONOLOGÍA Y ORTOGRAFÍA}

- Consolidación y refuerzo del reconocimiento y producción de los fonemas vocálicos y consonánticos.

- Insistencia en los fonemas que presentan mayor dificultad: $b / p, d / t, g / k, n / n g$, $\mathrm{j} / \mathrm{q} / \mathrm{x}, \mathrm{zh} / \mathrm{ch} / \mathrm{sh}, \mathrm{z} / \mathrm{c} / \mathrm{s}$.

- Insistencia en la transcripción de los fonemas anteriores.

- Reconocimiento de las variantes más sobresalientes de realización de los fonemas.

(2) Reconocimiento de la relajación articulatoria en lenguaje familiar y coloquial.

- Diptongos y triptongos.

- Estructura de la sílaba y separación silábica: “(cons.) vocal (nasal: alveolar y velar)".

(2) Ventajas e inconvenientes de un sistema fonológico y silábico de tanta simplicidad.

- Acento enfático.

- Entonación: refuerzo de los patrones característicos y estudio de otros especiales. Combinación de los distintos grupos fónicos que componen la oración.

- Entonaciones especiales en las oraciones interrogativas, exclamativas y adjetivas o de relativo.

- Entonaciones especiales en las oraciones con algún elemento topicalizado, focalizado o enfatizado.

(2) Refuerzo y ampliación de la entonación para las funciones comunicativas trabajadas. 
(2) Patrones melódicos específicos de ciertas estructuras sintácticas: anteposición de los complementos (dos posibilidades: 在街上//有很多人o 在街上有很多人) ; anteposición del verbo al sujeto (una sola unidad, como en 伊萨贝尔赢入; división de unidades en subordinadas; entonación en cláusulas explicativas y parentéticas.

(2) Ampliación de secuencias sencillas con entonación característica: refranes y poemas sencillos: 成语和简单的诗.

- Insistencia en los tonos.- reconocimiento y producción. Cambios tonales en 一, 七, 八, 不, 得, 背, 量. Tono shandi y variaciones morfofonológicas (un mismo carácter cambia de tono según desempeñe una u otra categoría gramatical: 背, 量 $\rightarrow \mathrm{N}$ y V)

- Insistencia en las palabras con la misma sílaba pero diferente tono (马 / 骂 / 玛 / 妈/码/吗/嘛, 买/卖/埋, 毛/猫/帽/貌, 慢/满/ 馒/谩)

(2) Refuerzo y ampliación de los caracteres homófonos pero no homógrafos (misma pronunciación y mismo tono pero distinta escritura:

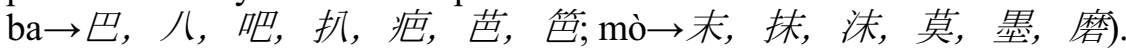

- Ritmo. Insistencia en la tendencia al ritmo binario y a las palabras bisílabas del chino mandarín (葡萄, 学校, 漂亮). Repercusiones en la sintaxis, en el léxico y en el lenguaje literario.

- Consolidación y ampliación de abreviaturas (北京大学 $\rightarrow$ 北大, 公共汽车 $\rightarrow$ 公车, 北京外语大学 $\rightarrow$ 北外).

- Consolidación y ampliación de siglas provenientes de otros idiomas (sobre todo del inglés: $H S K \rightarrow$ 汉语水平考试, AIDS o SIDA $\rightarrow$ 艾滋病, TOEFL $\rightarrow$ 托福 考试-, $\quad O N U \rightarrow$ 联合国, ONG $\rightarrow$ 非政府组织, NATO u OTAN $\rightarrow$ 北大西洋公约组织) (Ver Formación de Palabras).

- Consolidación y refuerzo del orden de los trazos. Alteraciones según la posición.

- Ortografía cuidada del vocabulario de uso: número de trazos, orden y proporción de las partes.

(2) Reconocimiento y uso de 3000 caracteres.

- Puntuación: usos del punto y aparte, punto y seguido, dos puntos, punto y coma, coma, coma enumerativa, comillas y subrayado.

\section{INTEGRACIÓN DE LOS RECURSOS LINGÜÍSTICOS Y LOS OBJETIVOS COMUNICATIVOS. AUTOEVALUACIÓN}

Además de los recursos lingüísticos, y basándonos en un manual sobre el vocabulario utilizado en las situaciones comunicativas más frecuentes de la vida cotidiana, válido para todos los idiomas, junto con el profesor Li Wan-Tang de la EOI de Madrid, hemos llevado a cabo su adaptación al chino (véase C. Marco y W. T Lee Jen 2007). Según el Marco, los recursos lingüísticos estarán al servicio de la competencia y situaciones comunicativas establecidas para cada nivel, y no al revés. 
Veamos a continuación, el índice con los temas tratados y una pequeña muestra del léxico utilizado en una de las situaciones comunicativas, p.ej. la de compras (C. Marco y W. T Lee Jen 2007: 5-6).

\section{Reglas de pronunciación del 汉语发音准则}

\section{Todo tipo de situaciones}

Fórmulas de saludo y presentación

Frases útiles (disculpa, petición, duda, acuerdo y desacuerdo)

La lengua

Las estaciones del año, los meses, los días de la semana y las horas

El tiempo

VIDA COTIDIANA

La familia

El aspecto físico de la persona

\section{LA CASA/EL PISO}

Cómo alquilar un piso

Un día laborable

En la ciudad.

¿Dónde se encuentra...?

¿Por dónde se va a...?

En el trabajo

Profesiones. En busca de trabajo

Contactos de negocios

En la escuela y en el instituto

En la universidad

En el restaurante, en la cafetería

De compras. En el

\section{各种情景}

礼仪方式及介绍

常用向子（致歉，请 求，疑问，同意与不

同意)

语文

四季，月份，星期， 时间

气候

\section{日常生活}

家庭

体能状况

家/房子

如何租房子?

工作日

在城市。你现在在哪

儿...?

对不起，请问到.....

怎么去?

在工作

职业。找职业

买卖接触

在小学和在中学

在大学

在餐馆, 在咖啡厅

买东西。在超级市场 
supermercado

De compras. En los grandes almacenes, en el centro comercial

En el médico

En el dentista

En la farmacia. En la óptica En correos. En el locutorio

En la peluquería.

En el salón de belleza

El automóvil. ¿Cómo alquilar un coche? En el taller

\section{TIEMPO DE OCIO}

Un día de descanso. Un fin de semana

Visita a la ciudad, lugares de interés y excursiones

En el teatro, en el concierto

En la naturaleza

Tiempo libre, deportes, hobbies

DE VIAJE

En el control de pasaportes y aduana

Un viaje en tren

Un viaje en autobús

Un viaje en avión

Un viaje en barco

En el banco.Cambio de

moneda/divisas

El hotel, el hostal y la

pensión

\section{SITUACIONES DE}

EMERGENCIA

En la comisaría

Un accidente de tráfico

BREVE COMPENDIO

GRAMATICAL

1.Tonos
买东西。在大卖场, 在购物中心

在医院

在牙医诊所

在药房, 在眼镜行

在邮局, 在电话亭

在理发店。

在发廊中心

汽车, 如何租车?

在修车行

\section{娱乐时间}

休息日，周末

参观城市，景点及旅

游

在剧院，在音乐会

大自然

休闲时间，运动，爱

好

旅行

检验护照及海关

搭火车旅行

搭汽车旅行

搭飞机旅行

搭船旅行

在银行

兑换钱币及外币

饭店，宾馆，招待所

\section{紧急状况}

在警句

交通事故

\section{简略文法内容}

声调 
2. Verbo

3. Sustantivo

动词

4. Adjetivo

名词

5. Pronombre

6. Clasificadores

形容词

代名词

7. Numerales

量词

8. Adverbios

数词

9. Coverbos

10.Partículas locativas

副词

介词

(posposiciones)

11. Conjunciones

方位助词

12. Partículas modales

连接词

oracionales

13. Interrogación

14. Comparación

语句助词

15. La construcción activa把

疑问句

比较

bă

16. La construcción

主动结构

pasiva被bèi

17. La construcción是....的

shi...de

18. Estructura y orden

被动结构

oracional

是... 的语句结构

向子结构

b- Ej.: De compras en unos grandes almacenes (C. Marco y W.T Lee 2007: 100113)

\begin{tabular}{|c|c|c|}
\hline Español & Chino中文 & Pronunciación \\
\hline $\begin{array}{l}\text { ¿Dónde hay unos } \\
\text { grandes almacenes } \\
\text { por aquí cerca? }\end{array}$ & $\begin{array}{l}\text { 这儿附近哪儿有大商场 } \\
\text { ? }\end{array}$ & $\begin{array}{l}\text { zhèr fùjìn năr yǒu dà } \\
\text { shāngchăng? }\end{array}$ \\
\hline $\begin{array}{l}\text { [Hay unos] } \\
\ldots \text {.. en el centro de } \\
\text { la ciudad } \\
\ldots \text { cerca del casco } \\
\text { histórico }\end{array}$ & $\begin{array}{l}\ldots \text { 在市中心 } \\
\ldots \text { 历史古迹附近 } \\
\\
\text { [有几家] }\end{array}$ & $\begin{array}{l}\text {...zài shì zhōngxīn } \\
\text {...lìshǐgǔjì füjìn }\end{array}$ \\
\hline $\begin{array}{l}\text { ¿Qué secciones hay } \\
\ldots \text { en la planta } \\
\text { baja? } \\
\text {... en la primera } \\
\text { planta? } \\
\text {... en la segunda }\end{array}$ & $\begin{array}{l}\cdots \text { 底层 } \\
\cdots \text { 二层 } \\
\cdots \text { 二层 }\end{array}$ & ...mài shénme? \\
\hline
\end{tabular}




\begin{tabular}{|c|c|c|}
\hline \multirow[b]{2}{*}{\begin{tabular}{|l|} 
planta? \\
En la planta baja se \\
encuentra la sección \\
$\ldots$ de artículos de \\
regalo \\
... de lencería \\
$\ldots$ de \\
electrodomésticos \\
.. de artículos de \\
radio y televisión \\
... de muebles \\
\end{tabular}} & & \\
\hline & $\begin{array}{l}\text { 在大楼底层卖 } \\
\ldots \text { 礼品 } \\
\ldots \text {.衣 } \\
\ldots . \text { 小家电 } \\
\ldots . . \text { 音响电视 } \\
\ldots \text { 家具 }\end{array}$ & $\begin{array}{l}\text { zài dàlóu dǐcéng mài } \\
\text {...lǐpǐn } \\
\text {...nèiȳī } \\
\text {..xiăo jiādiàn } \\
\text {...yīnxiăng diànshì } \\
\text {...jiājù }\end{array}$ \\
\hline $\begin{array}{l}\text { ¿Dónde está la/el } \\
\text { sección/ } \\
\text { departamento } \\
\text {... de ropa de } \\
\text { caballero? } \\
\text {... de ropa de } \\
\text { señora? } \\
\ldots \text { de ropa para } \\
\text { niños/ } \\
\text { infantil? } \\
\text {... de calzado? } \\
\text {... de deportes? } \\
\text {... de } \\
\text { alimentación? } \\
\text {... de perfumería? } \\
\ldots \text { de artículos para } \\
\text { el hogar? }\end{array}$ & 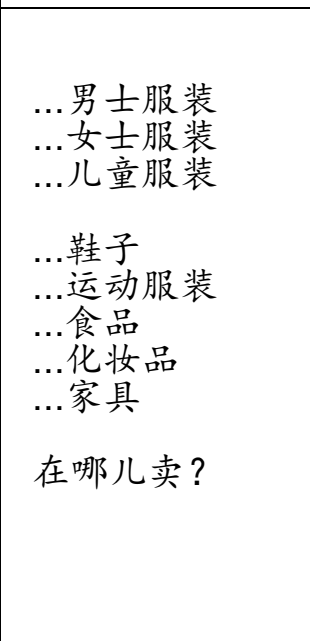 & $\begin{array}{l}\text {...nánshì fúzhuāng } \\
\text {...nüshí fúzhuāng } \\
\text {...ếrtóng fúzhuāng } \\
\text {...xiézi } \\
\text {...yùndòng fúzhuāng } \\
\text {...shípǐn } \\
\text {...huàzhuāng pǐn } \\
\text {...jiājūu } \\
\text { zài năr mài? }\end{array}$ \\
\hline ESPAÑOL & 中文 & PRONUNCIACIÓN \\
\hline $\begin{array}{l}\text { [Está] } \\
\ldots . \text { en la tercera } \\
\text { planta } \\
\ldots \text { en la quinta } \\
\text { planta } \\
\text {... en la planta } \\
\text { sótano }\end{array}$ & $\begin{array}{l}{[\text { 在] }} \\
\ldots \text { 三层 } \\
\ldots . \text { 五层 } \\
\ldots \text {. 地下一层 }\end{array}$ & $\begin{array}{l}\text { [zài] } \\
\text {... sāncéng } \\
\text {...wǔcéng } \\
\text {...dìxià yīcéng. }\end{array}$ \\
\hline $\begin{array}{l}\text { ¿Cómo se va a la/al } \\
\text { sección/departamento } \\
\text { de...? }\end{array}$ & 去......部怎么走? & qù ... bù zěnme zǒu? \\
\hline $\begin{array}{l}\text { Suba por las } \\
\text { escaleras mecánicas } \\
\text { hasta la cuarta } \\
\text { planta }\end{array}$ & 坐扶手梯到四楼 & zuò fúshǒutī dào sìlóu \\
\hline $\begin{array}{l}\text { Busco } \\
\ldots \text { una corbata } \\
\ldots \text { la sección de } \\
\text { camisas de }\end{array}$ & $\begin{array}{l}\text { 我想买 } \\
\ldots \text { - 条领带 } \\
\text {...男士祄衫 }\end{array}$ & $\begin{array}{l}\text { wǒxiăng măi } \\
\text {...yìtiáo lǐngdài. } \\
\text {...nánshì chènshān }\end{array}$ \\
\hline
\end{tabular}




\begin{tabular}{|c|c|c|}
\hline caballero & 在哪儿卖? & zài năr mài? \\
\hline $\begin{array}{l}\text { ¿Desea comprar } \\
\text { algo? }\end{array}$ & 您想买什么? & nín xiăng măi shénme? \\
\hline $\begin{array}{l}\text { No, gracias, estoy } \\
\text { sólo viendo, } \\
\text { echando un vistazo }\end{array}$ & 不，谢谢。我只是看看 & bù, xièxie. wǒ zhǐ shì kànkan \\
\hline $\begin{array}{l}\text { ¿Podría } \\
\text {... ayudarme a } \\
\text { escoger un bolso } \\
\text { de señora? } \\
\ldots \text {.. traerme otro par } \\
\text { de zapatos, pero } \\
\text { de otro modelo? }\end{array}$ & $\begin{array}{l}\text { 能帮我 } \\
\text { ‥ 下拿一这个女士包 } \\
\text { ․ 拿另外一双鞋, } \\
\text { 但是拿另外一款好吗 } \\
\text { ? }\end{array}$ & $\begin{array}{l}\text { néng bāng wǒ } \\
\text {...ná yíxià zhè gè nŭshi bāo } \\
\text { ‥ nálìngwài yíshuāng xié, } \\
\text { dànshì ná lìngwài yíkuăn hăo } \\
\text { ma? }\end{array}$ \\
\hline $\begin{array}{l}\text { ¿Tendría zapatos de } \\
\text { otro color/número? }\end{array}$ & $\begin{array}{l}\text { 有其它（颜色/号码）的 } \\
\text { 吗? }\end{array}$ & $\begin{array}{l}\text { yǒu qītā (yánsè/hàomă) } \\
\text { de ma? }\end{array}$ \\
\hline $\begin{array}{l}\text { ¿Qué número de } \\
\text { calzado gasta? }\end{array}$ & 您要多少号？ & nín yào duōshao hào? \\
\hline $\begin{array}{l}\text { Gasto... el treinta y } \\
\text { ocho }\end{array}$ & 我要三十八号 & wǒ yào sānshíbā hào \\
\hline ¿Puedo ayudarle? & 我能帮您吗? & wǒ néng bāng nín ma? \\
\hline $\begin{array}{l}\text { ¿Podría } \\
\text { aconsejarme qué } \\
\text { bolso me va mejor? }\end{array}$ & $\begin{array}{l}\text { 您觉得哪个包更适合我 } \\
?\end{array}$ & $\begin{array}{l}\text { nín juéde nă gè bāo gèng héshì } \\
\text { wô? }\end{array}$ \\
\hline Español & 中文 & Pronunciación \\
\hline $\begin{array}{l}\text { En seguida le } \\
\text { atiendo, tan pronto } \\
\text { acabe con este } \\
\text { cliente } \\
\text { Un momento, por } \\
\text { favor }\end{array}$ & $\begin{array}{l}\text { 接待完这位顾客后，马 } \\
\text { 上接待您。 } \\
\text { 请稍等 }\end{array}$ & $\begin{array}{l}\text { jiēdài wán zhè wèi gùkè hòu, } \\
\text { măshang jiēdài nín } \\
\text { qǐng shāoděng }\end{array}$ \\
\hline $\begin{array}{l}\text { ¿Puedo } \\
\text { probármelo? } \\
\text { ¿Dónde me puedo } \\
\text { probar...? } \\
\text { ¿Dónde está el } \\
\text { probador? }\end{array}$ & $\begin{array}{l}\text { 我能试一试吗? } \\
\text { …我在哪儿试...? } \\
. \\
\text {..试衣间在哪儿? }\end{array}$ & $\begin{array}{l}\text { wǒ néng shì yí shì ma? } \\
\text {...wǒ zăi năr shì....? } \\
\text {...shìyī jiān zài năr? }\end{array}$ \\
\hline $\begin{array}{l}\text { El probador está al } \\
\text { fondo, detrás de } \\
\text { aquella estantería }\end{array}$ & $\begin{array}{l}\text { 试衣间在最里面, } \\
\text { 那个货架后边 }\end{array}$ & $\begin{array}{l}\text { shìyī jiān zài zuì lǐmiàn, } \\
\text { nà gè huòjiào hòubian }\end{array}$ \\
\hline $\begin{array}{l}\text { ¿Cómo me queda } \\
\text { este traje? }\end{array}$ & 我穿这套西服怎么样？ & $\begin{array}{l}\text { wǒ chuān zhè tào xīfú zěnme } \\
\text { yàng? }\end{array}$ \\
\hline $\begin{array}{l}\text { Es un poco } \\
\text { pequeño/grande } \\
\text { Me está estrecho } \\
\text { de hombros }\end{array}$ & $\begin{array}{l}\text { 有点儿（小/大） } \\
\text { 肩有点窄 }\end{array}$ & $\begin{array}{l}\text { yǒudiănr (xiǎo/dà) } \\
\text { jiān yǒu diăn zhăn }\end{array}$ \\
\hline El pantalón me//le & 卧床这条裤子有点（短) & wòchuáng zhè tiáo kùzi yǒu \\
\hline
\end{tabular}




\begin{tabular}{|c|c|c|}
\hline está corto/largo & 长) & diăn (duăn/cháng) \\
\hline $\begin{array}{l}\text { Las mangas son } \\
\text { cortas }\end{array}$ & 袖子短 & yòuzi duăn. \\
\hline $\begin{array}{l}\text { Este vestido me } \\
\text { está estrecho } \\
\text { Tráigame otro } \\
\text { vestido de una/dos } \\
\text { talla/-as mayor }\end{array}$ & $\begin{array}{l}\text { 我穿这条套裙有点小 } \\
\text { 请给我换大（一/两） } \\
\text { 号的 }\end{array}$ & $\begin{array}{l}\text { wǒ chuān zhè tiáo tàoqún yǒu } \\
\text { diăn xiăo } \\
\text { yǒu gěi wǒ huàn dà (yì/liăng) } \\
\text { hào de }\end{array}$ \\
\hline $\begin{array}{l}\text { Este vestido le } \\
\text { queda muy bien } \\
\text { Este vestido es muy } \\
\text { grande para mí } \\
\text { Tráigame otro } \\
\text { vestido de una/dos } \\
\text { talla/-as menor }\end{array}$ & $\begin{array}{l}\text { 您穿这条裙子很合适 } \\
\text { 我穿这裙子很大 } \\
\text { 请给我换小 (一/两) 号 } \\
\text { 的 }\end{array}$ & $\begin{array}{l}\text { nín chuān zhè tiáo qúnzi hěn } \\
\text { héshì } \\
\text { wǒ chuān zhè tiáo qúnzi hěn dà } \\
\text { qùng gěi wǒ huàn xiăo (yí/liăng) } \\
\text { hào de }\end{array}$ \\
\hline $\begin{array}{l}\text { Necesito una talla } \\
\text { más } \\
\text { grande/pequeña }\end{array}$ & 我要（大/小）一号的 & wǒ yào (dà/xiăo) yí hào de \\
\hline $\begin{array}{l}\text { No me gusta este } \\
\text { modelo }\end{array}$ & 我不喜欢这个款式 & wǒ bù xǐhuān zhè gè kuănshì \\
\hline Español & 中文 & Pronunciación \\
\hline $\begin{array}{l}\text { ¿Tiene } \\
\ldots \text { otro modelo? } \\
\ldots \text { otro color? } \\
\ldots \text { otro número? }\end{array}$ & $\begin{array}{l}\text { 有 } \\
\ldots \text { 其它款式 } \\
\text { ‥其它颜色 } \\
\ldots \text { 其它号码 } \\
\end{array}$ & $\begin{array}{l}\text { yǒu } \\
\text {...qîtākuănshì } \\
\text {...qītāyánsè } \\
\text {...qītāhàomă) }\end{array}$ \\
\hline $\begin{array}{l}\text { Sí, en seguida le } \\
\text { traigo varios }\end{array}$ & $\begin{array}{l}\text { 有, 我马上给您拿几个 } \\
\text { 来 }\end{array}$ & $\begin{array}{l}\text { yǒu, wǒ măshàng gěi nín ná jǐ } \\
\text { gè lái }\end{array}$ \\
\hline Me quedo con esto & 我买这个 & wǒ măi zhè gè \\
\hline Me lo llevo & 我买了 & wǒ măi le \\
\hline $\begin{array}{l}\text { Por favor, } \\
\text { envuélvamelo }\end{array}$ & 请给我打好包装 & qǔng gěi wǒ dǎ hǎo bāozhuāng \\
\hline $\begin{array}{l}\text { ¿El precio tiene } \\
\text { el IVA incluido? }\end{array}$ & 价格包括增值税吗? & jiàgé bāokuò zēngzhíshuì ma? \\
\hline $\begin{array}{l}\text { Sí, todos nuestros } \\
\text { precios tienen el } \\
\text { IVA incluido }\end{array}$ & $\begin{array}{l}\text { 是的, 我们所有的价格 } \\
\text { 都包括增值税 }\end{array}$ & $\begin{array}{l}\text { shì de, wǒmen suǒyǒu de jiàgé } \\
\text { dōu bāokuò zēngzhíshuì }\end{array}$ \\
\hline $\begin{array}{l}\text { ¿Dónde está la } \\
\text { caja? }\end{array}$ & 收银台在哪儿? & shōuyíntái zài năr? \\
\hline $\begin{array}{l}\text { [Está] al final del } \\
\text { pasillo a la derecha }\end{array}$ & 在这条路右边的尽头 & zài zhè tiáo lù yòubian de jìntóu \\
\hline $\begin{array}{l}\text { ¿Puedo pagar } \\
\text {.. con tarjeta de } \\
\text { crédito? }\end{array}$ & $\begin{array}{l}\text { 我可以用 } \\
\text { …信用卡 } \\
\ldots . \text { 现金/ }\end{array}$ & $\begin{array}{l}\text { wǒ kěyǐyòng } \\
\text {..xxìnyòngkă } \\
\text {...xiànjīn/n/ }\end{array}$ \\
\hline
\end{tabular}




\begin{tabular}{|l|l|l|}
\hline $\begin{array}{l}\text {... al contado/ } \\
\text { en efectivo? }\end{array}$ & \multicolumn{1}{|c|}{ 现仯 } & xiàn chāo \\
\hline $\begin{array}{l}\text { Necesito el tícket/ } \\
\text { recibo de compra }\end{array}$ & 我需要购物收据 & wǒ xūyào gòuwù shōujù. \\
\hline $\begin{array}{l}\text { Aquí tiene el } \\
\text { tique/recibo y la } \\
\text { vuelta }\end{array}$ & $\begin{array}{l}\text { 这是您的购物收据 } \\
\text { 和找回的零头 }\end{array}$ & $\begin{array}{l}\text { zhè shì nín de gòuwù shōujù } \\
\text { hé zhăo huí de líng tou }\end{array}$ \\
\hline
\end{tabular}

También quiero señalar que desde el curso 2006-7 en nuestras clases de chino para españoles (impartidas en el CSIM, en la Facultad de Filología de la UCM y a las que puede apuntarse cualquier alumno de cualquier facultad) empezamos ya a aplicar, tal como propone el Marco Europeo de las Lenguas, el método de establecer para cada unidad del programa los Objetivos comunicativos y su correspondiente Autoevaluación por parte del alumno. En cada unidad se recogen, y el alumno se autoevalúa, las 5 destrezas, aunque según los casos puede predominar una u otra. Conviene hacer notar que, en un principio, algunos estudiantes opusieron cierta resistencia pero, una vez acostumbrados, reconocieron que esta labor les ayudaba a "tomar conciencia" y a adquirir mayor autonomía en su proceso de aprendizaje. A continuación ponemos tres ejemplos a modo de referencia: alquilando un piso, en mi barrio y hablando del tiempo.

\begin{tabular}{|l|l|l|}
\hline CL & Comprensión Lectora & 阅读能力 \\
\hline CO & Comprensión Oral & 听力理解 \\
\hline EO & Expresión Oral & 口头表达能力 \\
\hline IO & Interacción Oral & 对话能力 \\
\hline EE & Expresión Escrita & 书写能力 \\
\hline
\end{tabular}

\begin{tabular}{|c|c|c|}
\hline \multicolumn{2}{|c|}{ LECCIÓN 14 - Alquilar un piso 租屋 } & Autoevaluación \\
\hline \multicolumn{2}{|c|}{ PUEDO... 我能.. } & \\
\hline CL & Entender un anuncio sobre un piso que se alquila. 了解租屋广告 & \\
\hline $\mathrm{CO}$ & $\begin{array}{l}\text { Entender un diálogo sobre las habitaciones y muebles que } \\
\text { contiene un piso. 了解房屋大房可双家具的㑤术 }\end{array}$ & \\
\hline EO & $\begin{array}{l}\text { Describir las características del piso que deseo alquilar. } \\
\text { 描术你想租的房子特征 }\end{array}$ & \\
\hline IO & $\begin{array}{l}\text { Mantener un diálogo con el propietario del piso que voy a } \\
\text { alquilar. } \\
\text { 维持与房本的对话 }\end{array}$ & \\
\hline $\mathrm{EE}$ & $\begin{array}{l}\text { Escribir un anuncio en un periódico sobre las características del } \\
\text { piso que estoy buscando. } \\
\text { 兯你想租用的房子特正 }\end{array}$ & \\
\hline
\end{tabular}


Esa autoevaluación la llevará a cabo el alumno tras haber estudiado los siguientes contenidos en la lección de clase correspondiente:

\section{UNIDAD 14 第十四果}

- Alquilar un piso 租房子:

. ¿Cuántas habitaciones tiene? [房间 salón, cocina, dormitorio, cuarto de baño, pasillo, terraza...]

. ¿Qué muebles tiene? [ 家具 mesa, silla, sofá, armario, lámpara, cama...]

- ¿Es necesario dejar una señal?

. La luz, el agua y el gas jestán incluidos en el alquiler o se pagan aparte?

. ¿Está bien comunicado? Cerca hay metro, autobús, estación de tren...

\begin{tabular}{|c|c|c|}
\hline \multicolumn{2}{|c|}{ LECCIÓN 15 - En mi barrio 在我的社区 } & Autoevaluación \\
\hline \multicolumn{3}{|c|}{ PUEDO... 我能.. } \\
\hline $\mathrm{CL}$ & $\begin{array}{l}\text { Entender los carteles de los edificios y establecimientos de mi barrio } \\
\text { (cine, banco, correos, colegio, biblioteca, gimnasio, etc.) } \\
\text { 了解社区内的广告及海报（如电影，银打，由柌，图井染官，体有馆， } \\
\text { 等的海报） }\end{array}$ & \\
\hline $\mathrm{CO}$ & $\begin{array}{l}\text { Entender un diálogo entre personas que hablan de las tiendas y } \\
\text { establecimientos } \\
\text { 了解社区商店及其设施的对话 }\end{array}$ & \\
\hline $\mathrm{EO}$ & $\begin{array}{l}\text { Preguntar dónde se encuentran diferentes tiendas y establecimientos. } \\
\text { 询可不同客占及设施的位置 }\end{array}$ & \\
\hline $\mathrm{IO}$ & Mantener un diálogo sobre mi barrio. 维持有突社的对话 & \\
\hline $\mathrm{EE}$ & $\begin{array}{l}\text { Describir mi barrio. } \\
\text { 描述我的衤区 }\end{array}$ & \\
\hline
\end{tabular}

\begin{tabular}{|c|c|c|}
\hline \multicolumn{2}{|c|}{ LECCIÓN 19 - En torno al clima 气候 } & Autoevaluación \\
\hline & PUEDO... 我能.. & \\
\hline $\mathrm{CL}$ & $\begin{array}{l}\text { Entender la previsión del tiempo que se anuncia en un periódico. } \\
\text { 了解及的大气预告 }\end{array}$ & \\
\hline $\mathrm{CO}$ & $\begin{array}{l}\text { Entender la previsión del tiempo que se hace por televisión. } \\
\text { 了解电视上的天气预报 }\end{array}$ & \\
\hline EO & $\begin{array}{l}\text { Contar cómo es el clima en mi provincia y en mi país. } \\
\text { 陈述我 (居住) 的省分及玨家的天气 }\end{array}$ & \\
\hline IO & $\begin{array}{l}\text { Hablar con un compañero sobre el clima en nuestros respectivos } \\
\text { países y/o provincias. 与同学谈及个所属王家或省/分的天气的对话 }\end{array}$ & \\
\hline
\end{tabular}




\begin{tabular}{|c|c|}
\hline EE & 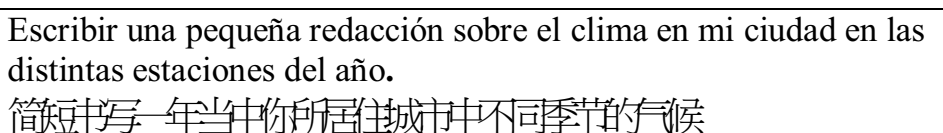 \\
\hline
\end{tabular}

\section{INTEGRACIÓN DE LA COMPETENCIA LINGÜÍSTICA CON LA COMPETENCIA SOCIOCULTURAL Y LA COMUNICACIÓN NO VERBAL}

Como ya hemos mencionado, falta por armonizar los contenidos lingüísticos con las situaciones comunicativas y con los objetivos del Marco. Resultaría muy interesante que este vacío fuera llenado con trabajos de investigación e, incluso, tesis doctorales. Actualmente varios de nuestros doctorandos, que previamente han cursado el Máster Oficial de Enseñanza del Español como LE / L2 en Filología, están investigando sobre este tema; resultaría muy enriquecedor que se sumaran también investigadores de Ciencias de la Educación. El estudio, por supuesto, sería de gran relevancia tanto para la enseñanza del chino a hispanohablantes como para la enseñanza del español a hablantes chinos.

El Marco contiene, además, una dimensión sociocultural. Por eso, el docente de una lengua extranjera, de la lengua china en este caso, ha de tener una buena formación teórica y metodológica que, aunque no siempre manifieste de forma explícita, al menos ha de usar como medio o instrumento para conseguir que sus alumnos, aparte de dominar el código lingüístico (nivel fonológico, morfosintáctico y léxico-semántico), sean también capaces de actuar de forma comunicativamente adecuada en un contexto determinado. De ahí la importancia de llevar también al aula los factores socioculturales y la comunicación no verbal (F. Poyatos 1994: 35-60). Dentro de esta última tratamos el paralenguaje (entonación, volumen, pausas y ritmo al hablar), la quinésica (gestos y posturas corporales), la proxémica (gestión del espacio en la conversación) y la cronémica (concepción y uso del tiempo). Todo ello supone trabajar con diferentes destrezas de manera integrada, las cuales facilitarán al alumno las herramientas para adquirir estrategias de análisis, comparación, contraste y reflexión acerca de realidades diversas. Esta toma de conciencia evitará caer en tópicos y prejuicios y desarrollará actitudes positivas de cara al pluralismo cultural y lingüístico de la sociedad internacional.

Aunque me parece que no es poca la dificultad que presenta discriminar qué partes del rico repertorio de alternativas comportamentales constituyen esa cultura estándar nacional, que debemos enseñar, común a las distintas geografías y a los distintos grupos sociales, como profesores de lenguas extranjeras debemos hacer, al menos, que nuestros alumnos se den cuenta de que una comunicación efectiva requiere descubrir las imágenes condicionadas culturalmente que son evocadas en la mente de los nativos cuando hablan, actúan y reaccionan en el mundo que les rodea. Comprender el contexto cultural de comunicación es fundamental para descodificar con acierto un mensaje. Y esto cobra una especial relevancia en una sociedad tan compleja y paradójica como la que conforma la China actual, donde la búsqueda de matices resulta imprescindible. 
I. Iglesias (2000: 4-10) insiste en que nuestra cultura nos enseña qué ver y qué ignorar, pero una persona recién asomada a otra cultura no sabe qué ver, ni generalmente, cómo interpretar lo que ve. Está a la deriva en un mar de datos y generalmente tratará de interpretarlos proyectando sobre ellos sus propias experiencias. Para evitar este peligro podemos explotar los patrones culturales contrastados usándolos como punto de entrada en la cultura meta. Una vez dentro se animará al estudiante a que descubra que ese comportamiento aparentemente exótico tiene perfecto sentido si se ve dentro del contexto del resto de la cultura. De este forma se intentará evitar en el alumno el llamado "efecto escaparate", es decir, el observar otra cultura con las gafas de la propia, lo cual desemboca irremediablemente en el "síndrome de Nancy"; se llama así a la audacia con la que se suelen, interpretar -o mejor malinterpretar- las conductas de los usuarios de esa lengua, sin conocer la mayoría de las veces la verdadera intención que las ha guiado porque casi siempre cobran su verdadero sentido dentro de la totalidad de la cultura de origen, porque "los modos de pensar, actuar y sentir que definen cada cultura se adquieren socialmente" (I. Iglesias 2000: 6).

Las estrategias de negociación y normas de protocolo también han de incluirse en nuestro estudio. China esta de moda. Su crecimiento espectacular atrae cada vez más a los empresarios españoles que buscan una oportunidad en el coloso asiático. Pero, hacer negocios en China puede convertirse en una pesadilla si no se está preparado. Las diferencias culturales son tan bastas que alcanzan a todos los aspectos del mundo empresarial: negociación, contratos, legislación o una simple cena de trabajo. Ya existen cursos especializados, algunos con lista de espera. Por eso habrán de estudiarse las guanxi 关系o relaciones sociales y dar respuesta a una serie de preguntas frecuentes:

- ¿Qué hacer con una tarjeta de visita?

- ¿Cómo saludar y despedirse?

- ¿Cómo vestirnos? ¿con traje o de manera más informal?

- ¿Cómo dirigirsnos a nuestro interlocutor?

- ¿Cómo hay que interpretar la puntualidad / impuntualidad?

- ¿Hasta qué punto hay que respetar las jerarquías?

- ¿Qué tipo de regalos son aconsejables y cuáles conviente evitar?

- ¿Regatear e insinuar o ser claro y directo?

- ¿Qué temas es conveniente mencionar y/o evitar en una comida de negocios? (cuestiones políticas, religiosas, familiares...). ¿Cómo brindar?

- ¿Cómo formalizar un contrato?

- ¿Cómo resolver un conflicto si el marco legal no está bien desarrollado?

- ¿Ser audaz o comedido?

- ¿Es imprescindible, aparte de un buen intérprete, un buen "mediador cultural"?

- ¿Cómo interpretar determinados gestos?

- ¿Cómo interpretar las distancias?

Etc. 


\section{VÍNCULOS DE INTERÉS PARA HISPANOHABLANTES QUE ESTUDIAN CHINO}

A continuación señalo 13 vínculos que creemos pueden resultar útiles tanto para el profesor como para el estudiante hispanohablante de chino. Se refieren a temas muy variados y de actualidad: lengua, sociedad, política, educación, cine, viajes, juegos, publicaciones, etc.

1- Casa Asia: todo tipo de noticias relacionadas con China y Asia en general, cursos, publicaciones, etc. Suscripción gratuita al Boletín: política, sociedad, economía, sucesos, etc.

http://cav.casaasia.org:8000/mailman/listinfo/actualidad

2- Chinaviva

http://www.chinaviva.com/ etc.

Lengua, cultura (arte, historia...), negocios, viajes, libros y manuales publicados,

3- Embajada china:

http://www.embajadachina.es/esp/

Política, sociedad, educación, ciencia, noticias, concursos, becas, adopciones...

4- Para preparar el Examen Internacional de Chino (HSK): http://www.hsk.org.cn/

Contiene muchos ejercicios sobre gramática y lengua en general, organizados por niveles.

5- Instituto Igadi

http://www.igadi.org/index.html

Selección de artículos y noticias sobre la política y sociedad chinas.

6- Observatorio de la política china:

http://www.politica-china.org/

7- Diccionario chino-español:

Búsqueda por carácter chino, por pronunciación en pinyin o directamente en español.

Más de 30000 entradas, nombres propios, expresiones, frases hechas.. http://www.chino-china.com/diccionario

8- Chinochano:

http://chinochano.zoomblog.com/

En China: preparar el viaje, viajar por distintas regiones, buscar piso, buscar trabajo, contactar con hispanos, qué y dónde comer, etc.

9- Canciones chinas. Aprenda chino cantando http://www.chino-china.com/canciones/

10- Estudios de Posgrado a Distancia (China):

http://www.iaeu.es/caratula/asia/

Para estudiar lengua, literatura, arte, historia, cine, etc.

11- Estudios sobre Lingüística Aplicada y Lingüística Contrastiva (chino y otras lenguas): fonología, morfología, sintaxis y semántica. 
http://www.usc.edu/schools/college/ealc//chinling/

12- Parol-Júpiter: http://www.parol.es/

Fotos, vídeos, artículos, viajes, vínculos, etc.

13- Annanasia: http://annanasia.com.com/

Fotos, vídeos, artículos, etc.

\section{CONCLUSIONES}

Y ya para terminar, sólo me queda insistir una vez más en los grandes vacíos y necesidades que existen en lo referente a la adaptación de la enseñanza, aprendizaje y evaluación del "Chino para hispanohablantes" dentro de las directrices de Marco Común Europeo y animar a los lectores a seguir reflexionando e investigando en la armonización-integración de los contenidos lingüísticos (nivel fonológico, morfosintáctico y léxico-semántico), con los factores socioculturales y con la comunicación no verbal. Se trata de un campo muy interesante y de gran actualidad que puede dar lugar a futuros trabajos de investigación y tesis doctorales. Además, queremos mencionar que la actitud del profesor, junto a su formación teóricopráctica, es también un factor fundamental: las correcciones han de hacerse con tacto y sin herir la sensibilidad del alumno, para evitar que pierda la confianza en sí mismo y luego no se atreva a comunicarse; el análisis de errores nos lleva a comprender que éstos son inevitables, positivos y naturales en el proceso de aprendizaje. El docente deberá intentar despertar el interés pues, parafraseando a F. Savater, un estudiante no es una botella que hay que llenar, sino un fuego cuya llama hay que encender, lo cual confirmará asimismo el dicho chino de que "un buen profesor engendra buenos discípulos”: 名师出高徒 míngshī chū gāotú.

\section{REFERENCIAS BIBLIOGRÁFICAS}

CONSEJO DE EUROPA (2002): Marco Común Europeo de Referencia para las Lenguas: aprendizaje, enseñanza, evaluación, Ministerio de Eduación, Cultura y Deporte -Instituto Cervantes, Anaya. En internet: http://cvc.cervantes.es/obref/marco.

FERMOSO, Paciano (ed.) (1992), Educación intercultural: la Europa sin fronteras, Madrid, Narcea.

IGLESIAS CASAL, Isabel (1999): "Comunicación intercultural y enseñanza de lenguas extranjeras: hacia la superación del etnocentrismo", Boletín de ASELE, $\mathrm{n}^{\circ}$ 21: 13-23.

IGLESIAS CASAL, Isabel (2000): "Diversidad cultural en el aula de ELE: la interculturalidad como desafío y como provocación", Especulo, Universidad Complutense de Madrid. 
MARCO MARTÍNEZ, Consuelo y LEE JEN, Wan-Tang (2003): Método de chino para hispanohablantes.- nivel elemental (edición chino-español), Ediciones YouFeng, París.

MARCO MARTÍNEZ, Consuelo y LEE JEN, Wan-Tang (2006): Método de chino para hispanohablantes II.- nivel intermedio (edición chino-español), Ediciones You-Feng, París.

MARCO MARTÍNEZ, Consuelo y LEE JEN, Wan-Tang (2007): Chino para españoles. Adaptación del léxico y de las situaciones comunicativas del HSK al Marco Común Europeo, Centro de Lingüística Aplicada, Ed. Palas Atenea, Madrid.

MARCO MARTÍNEZ, Consuelo: "Recursos lingüísticos del nivel intermedio (1 y 2) para la enseñanza de la lengua china a españoles en el contexto del Marco Común Europeo", integrado en el Desarrollo del Currículo de las Nuevas Enseñanzas de Idiomas de régimen especial, según establece la Ley Orgánica 2/2006, del 3 de mayo, de Educación: estudio encargado por la Consejería de Educación de la Comunidad de Madrid y publicado en el BOCAM del 22 de junio de 2007. Sirve de referencia para las escuelas oficiales de idiomas.

MARCO MARTÍNEZ, Consuelo: "Recursos lingüísticos del nivel avanzado (1 y 2) para la enseñanza de la lengua china a españoles en el contexto del Marco Común Europeo", integrado en el Desarrollo del Currículo de las Nuevas Enseñanzas de Idiomas de régimen especial, según establece la Ley Orgánica 2/2006, del 3 de mayo, de Educación: estudio encargado por la Consejería de Educación de la Comunidad de Madrid y publicado en el BOCAM del 30 de julio de 2008. Sirve de referencia para las escuelas oficiales de idiomas.

POYATOS, Fernando (1994): La comunicación no verbal.- Paralenguaje, Kinésica e interacción, Madrid, Istmo, pp. 35-60.

WWW: PÁGINAS ELECTRÓNICAS SOBRE EL MCER:

- Traducción al español: http://cvc.cervantes.es/obref/marco

- Página general: http://www.coe.int

- División de Política Lingüística: http://culture.coe.int/lang y http://culture, coe.int/portfolio

- Centro Europeo de Lenguas Modernas (CELM): http://culture.coe.int/ecml - http://www.mec.es/europass

- http://www.mec.es/programas-europeos

- http://www.coe.int/portfolio .

- http://europass.cedefop.eu.int- 